\title{
HIV-1 hijacks the cell extracellular matrix to spread collectively and efficiently between
}

\section{T lymphocytes}

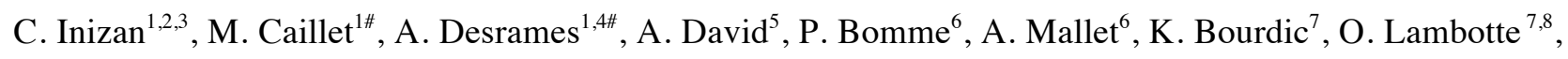
F. Boufassa ${ }^{9}$, M. Mesel-Lemoine ${ }^{10}$, F. Tangy ${ }^{10}$, G. Pancino ${ }^{11}$, H. Mouquet $^{12}$, T. Lagache $^{13,14}$, A. Dufour ${ }^{13}$, J.C. Olivo-Marin ${ }^{13}$, F.A. Rey ${ }^{1}$, A. Saez-Cirion ${ }^{5}$ and M.-I. Thoulouze ${ }^{1 *}$

\section{Affiliations :}

${ }^{1}$ Institut Pasteur, Unité de Virologie Structurale, Paris, France; CNRS UMR 3569; F-75724 Paris, France.

${ }^{2}$ Sorbonne Universités, UPMC Université Paris 6, F-75252 Paris, France.

${ }^{3}$ Institut Pasteur de Nouvelle-Calédonie, Unité de Recherche et d'Expertise- Dengue et Arboviroses F-98845 Nouméa, Nouvelle Calédonie.

${ }^{4}$ Université Sorbonne Paris Cité, Université Paris Diderot, Inserm, INTS, Unité Biologie Intégrée du Globule Rouge, LabEx GR-Ex, F-75739 Paris, France.

${ }^{5}$ Institut Pasteur, Unité HIV Inflammation et Persistance, Paris, France.

${ }^{6}$ Institut Pasteur, Ultrapole, Citech, F-75724 Paris, France.

7 Assistance Publique - Hôpitaux de Paris, Hôpital Bicêtre, Service de Médecine Interne et Immunologie clinique, F-94275 Le Kremlin-Bicêtre, France

${ }^{8}$ CEA, Université Paris Sud, INSERM U1184, Immunology of Viral Infections and Autoimmune Diseases (IMVA), IDMIT Department / IBFJ, F-92265 Fontenay-aux-Roses

${ }^{9}$ INSERM U1018, Université Paris Sud, Centre de recherche en Epidémiologie et Santé des Populations, F94275 Le Kremlin-Bicêtre, France

${ }^{10}$ Institut Pasteur, Unité de Génomique Virale et Vaccination, CNRS UMR3569, F-75724 Paris, France.

${ }^{11}$ Institut Pasteur, Unité Régulation des Infections Rétrovirales, Paris, France.

${ }^{12}$ Institut Pasteur, Laboratoire Réponse Humorale aux Pathogènes, F-75724 Paris, France.

${ }^{13}$ Institut Pasteur, Unité d'Analyse d'Images Biologiques, Paris, France CNRS UMR 3691, F-75724 Paris, France.

${ }^{14}$ Department of Biological Sciences, Columbia University, New York, NY, USA.

\# these authors contributed equally to this work

* Corresponding author : thoulouz@pasteur.fr 


\begin{abstract}
Collective transmission via structures containing several virions has recently emerged as a highly efficient mode of viral spread. Here, we demonstrate that HIV-1 spreads between T lymphocytes in the form of viral particles colonies that are concentrated and sheltered in an extracellular matrix (ECM) lattice enabling their collective transmission upon cell contacts. Intrinsically, ECM-clustered viruses infect $\mathrm{T}$ lymphocytes more efficiently than individual viral particles. They preserve HIV-1 transmission from antiretroviral treatment (ArT) and potent broadly neutralizing antibodies. We also show that collagen induced by HIV-1 infection controls the clustering of virions and their collective spread, thereby enhancing infectivity. CD4+ $\mathrm{T}$ cells from $\mathrm{HIV}-1$-infected patients produce and transmit ECM-virus clusters, supporting that they could be involved in vivo. This study provides new insights into modes of HIV-1 transmission and identifies a novel fundamental role for collagen in this process. HIV-1 spread via ECM-virus clusters may have important implications for viral dissemination and persistence, including during therapy.
\end{abstract}

Keywords: HIV-1, collective spread of viruses, extracellular matrix (ECM), collagen, cell-to-cell spread, virological synapse, bNAbs, ArT, persistence. 


\section{INTRODUCTION}

HIV-1 dissemination relies both on cell-free and cell-to-cell spread, the latter mode being more efficient in vitro (Chen et al., 2007; Dimitrov et al., 1993; Mazurov et al., 2010; Sourisseau et al., 2007). To date, the contribution of both modes to HIV-1 spreading in vivo remains unclear and likely depends on the course of infection and the anatomy of the body compartment colonized by the virus (Law et al., 2016b; Sewald et al., 2016). Cell-to-cell spread requires physical contacts between a donor cell (an infected cell producing viral particles or a cell carrying previously captured viral particles) and an uninfected target cell. By avoiding the dispersion of newly formed virions, cell-to-cell transmission increases the efficiency of HIV-1 spread, favors co-infection of target cells (Boulle et al., 2016; Del Portillo et al., 2011; Duncan et al., 2014; Law et al., 2016a) and reduces effectiveness of some antiretroviral treatments (ArT) as well as potent, broadly neutralizing antibodies (bNAbs)(Agosto et al., 2015; Malbec et al., 2013; McCoy et al., 2014; Reh et al., 2015; Titanji et al., 2013; Zhong et al., 2013). Thus, contact-mediated transmission may contribute to HIV-1 spread and persistence during therapy (Costiniuk and Jenabian, 2014; Titanji et al., 2013).

The spread of HIV-1 among CD4+ T cells, which serve both as vectors for HIV-1 dissemination and as the main site of viral replication in vivo (Haase, 1999; Murooka et al., 2012), is greatly enhanced by intercellular contacts in vitro (Chen et al., 2007; Dimitrov et al., 1993; Mazurov et al., 2010; Sourisseau et al., 2007). Different types of close intercellular contacts, referred as virological synapses (VS) here, as well as thin membrane extensions bridging infected and uninfected $\mathrm{T}$ cells, have been shown to enable HIV-1 transfer between T cells (Hubner et al., 2009; Jolly et al., 2004; Sherer et al., 2007; Sowinski et al., 2008). VS were initially described as long lasting junctions where viral particles accumulated during transfer from infected to non-infected T cell (Hubner et al., 2009; Jolly et al., 2004; Jolly et al., 2011; Rudnicka et al., 2009; Zhong et al., 2013). Infected T cells, either mononucleated or plurinucleated (syncitia), indeed transmit HIV-1 material through long-lasting junctions as initially described, but also through migrating junctions transiently formed with uninfected T cells (Chen et al., 2007; Hubner et al., 2009; Law et al., 2016a; Murooka et al., 2012; Symeonides et al., 2015). Thus, contact-mediated HIV-1 spread between T lymphocytes likely occurs 
in different forms - types of and dynamics of contacts- in vivo.

The way in which HIV-1 travels to efficiently spread between $\mathrm{T}$ cells remains unclear. Local concentration of individual virions at the VS, either cell-free or membrane-bound, is thought to be the main mechanism enabling the simultaneous transfer of multiple virions per target cell, therefore enhancing HIV-1 spread (Jolly, 2010; Mothes et al., 2010). However, it recently emerged that virusinduced structures that simultaneously transport groups of virions and enables their "en bloc" transmission greatly enhance viral infection by comparison with individual viral particles (AltanBonnet and Chen, 2015; Chen et al., 2015; Sanjuan, 2017). In the case of the Human T Cell Leukemia Virus type-1 retrovirus, which spreads almost exclusively via cell-cell contacts, the formation of a « viral biofilm » - colonies of virions embedded within a virus-induced scaffold of extracellular matrix (ECM) components and linker proteins - plays a crucial role in its transmission (Pais-Correia et al., 2010; Thoulouze and Alcover, 2011). Concentrating virions within such an adhesive and protective microenvironment may not only contribute to viral propagation in vivo but may also influence its persistence. In the case of HIV-1, diffusible infectious virions are massively released from infected T lymphocytes (Tsai et al., 1996). However, in co-culture systems, large patches of HIV-1 (Gag capsid protein) have been shown to reach the VS by lateral movements, at the surface of infected cells, prior to their capture by target $\mathrm{T}$ lymphocytes (Chen et al., 2007; Hubner et al., 2009). Within lymphoid tissues in humanized mice models, clusters of fully budded virions have been observed at the surface of infected T cells and along the track of migrating infected cells (Kieffer et al., 2017; Ladinsky et al., 2014; Symeonides et al., 2015). More importantly, in biopsies from non-treated HIV-1-infected patients, clusters of mature HIV-1 particles have been described together with isolated viruses within several lymphoid tissues (Orenstein, 2008). This opens up new interpretations regarding the participation of viral particle clusters in HIV-1 transmission.

To date, clustering and retention of HIV-1 at the surface of infected cells has been mainly considered as a cellular mechanism to restrict viral spread by limiting viral particle release. Indeed, the only cellular factor implicated in this process is tetherin/BST2, which notably prevents virus release by physically bridging nascent virions together and to the cell membrane (Andrew and Strebel, 2011; Martin-Serrano and Neil, 2011; Sauter, 2014; Strebel, 2013). Upon infection however, the HIV-1 
accessory protein Vpu limits tetherin exposure on the surface of infected cells, and thereby favors the release of individual virions (Neil et al., 2008; Van Damme et al., 2008). Transmission via cell-cell contacts seems to partially overcome the inhibitory effects of tetherin (Jolly et al., 2010; Zhong et al., 2013), further suggesting that membrane-bound and/or clusters of viruses could participate in HIV-1 spread. Regulating cell surface retention and clustering of HIV-1 particles could be a mean to adjust the mode and the efficiency of viral spread during the course of infection.

Here, we explored the role of membrane-bound HIV-1 in the infectivity of $\mathrm{T}$ cells by using a combination of cutting-edge imaging techniques along with functional approaches. We identified cellsurface-bound viruses clusters organized as biofilm-like structures as a major infectious pool involved in HIV-1 spread. As described for HTLV-1, infectious HIV-1 "biofilm" is composed of extracellular matrix (ECM) components (collagen, agrin) and linker proteins that physically hold together viral particles originated from a unique infected cell. CD4+ T cells isolated from HIV-1-infected patients produce and transmit ECM-enriched viral particle clusters, supporting their involvement in vivo. We show that Virus-ECM pools are intrinsically more infective than individual virions because they enable the "en bloc" spread of HIV-1 among T lymphocytes. We also demonstrate that ECM components composing these structures, and in particular collagen, control both the organization of viral particles at the cell surface and the resulting infectivity. Finally, we provide evidence that collective HIV-1 transfer in the form of virus-ECM clusters (VEC) accounts for most of the characteristics of contact-mediated transmission, including increased infectivity and reduced sensitivity to ArT and bNAbs. Thus, our findings identify ECM-linked HIV-1 colonies as new, highly infectious pools of virions, which must be taken into account in the design of therapeutic strategies. 


\section{RESULTS}

\section{Infectivity of HIV-1-infected T cells is largely attributable to membrane-bound pools of virions}

We first assessed the quantitative contribution of cell-surface viral material to HIV-1 transmission between CD4+ T lymphocytes. T lymphocytes chronically infected with HIV-1 (ACH2 cells) were subjected to gradual mechanical washes by extensive pipetting and were subsequently examined for remaining cell-associated viral capsid (CAp24, by flow cytometry) and virus transmission in coculture with reporter Jurkat T cells (LTR-Luc). Repeated mechanical washes led to up to a $40 \%$ reduction in cell-associated CAp24 and resulted in as much as a 55\% decrease in cell-associated infectivity (Fig. 1A \& Supplementary Fig. 1A). Mechanical treatment decreased cell-associated CAp24 to the same extent than subtilisin treatment commonly used to enzymatically remove the surface-bound viral material (Fig. 1A, left panel), without affecting neither the viability of infected cells (Supplementary Fig. 1B) nor their adhesive properties to fibronectin (Supplementary Fig. 1C). We ensured that luciferase activity was caused by actual HIV-1 infection of reporter target cells by using the reverse transcription inhibitor 3TC (Supplementary Fig. 1D). Surface-associated infectivity appeared to reside in firmly adhering extracellular viral material, as a single round of gentle pipetting of infected cells (single wash) only slightly decreased cell-associated CAp24 and did not significantly impact infectivity (Fig. 1A \& Supplementary Fig. 1A). Regardless of the intensity of mechanical washes, the decrease in cell-associated CAp24 correlated with the decrease in cell-associated mature HIV-1 matrix protein (MAp17) (Supplementary Fig. 1E), confirming that surface-associated viral material included mature viral particles. The contribution of $\mathrm{T}$ cell surface-associated viral material to HIV-1 spread was even more pronounced with primary CD4+ T cells infected in vitro with HIV-1 laboratory strain NL4-3. Milder mechanical washes were used in order to preserve the viability of infected primary $\mathrm{T}$ cells (not shown), leading to a $20 \%$ decrease in cell-associated CAp24 and corresponding to an $80 \%$ decrease in cell-associated infectivity (Fig. 1B). Thus, the reduction in cellassociated infectivity was mostly attributed to the removal of HIV-1 extracellular material from the surface of infected T cells. 


\section{Membrane-bound HIV-1 particles cluster as viral colonies at the surface of infected T cells}

We then characterized HIV-1 viral material at the surface of infected CD4+ T lymphocytes by confocal and electron microscopy in several types of HIV-1-infected $\mathrm{T}$ cell cultures. $\mathrm{T}$ cell lines chronically infected with HIV-1 (ACH2 and J1.1) and primary CD4+ T cells infected in vitro with either laboratory strains (NL4-3 and BaL), as well as primary virus isolates (DH12, Bx08 and W132), were examined. Confocal microscopy revealed bright extracellular clusters of HIV-1 Gag (HIV-1MAp24+ or CAp17+) at the surface of about 70\% of HIV-1-infected T cells, that were identified by their diffuse cytoplasmic CAp24+ ${ }^{+}$staining (Table 1). X4-tropic NL4-3, R5-tropic BaL, Bx08 and W132 and dual-tropic DH12 viruses similarly accumulated at the surface of infected T cells, indicating that HIV-1 retention at the surface of infected CD4+ T cells is independent of co-receptor tropism. Membrane-bound HIV-1 clusters sometimes localized within membrane invaginations or were attached to membrane protrusions and extensions (Fig. 1C \& Supplementary Fig. 2A,B). Similar clusters were also found at the surface of $\mathrm{T}$ cell syncytia formed in infected $\mathrm{T}$ cell cultures (shown for DH12 primary isolate; Supplementary Fig. 2C). HIV-1 viral material accumulating at the $\mathrm{T}$ cell surface was immunostained for HIV-1 Gag CAp24 and MAp17, as well as HIV-1 Env glycoprotein gp120 (Supplementary Fig. 2D), indicating that mature and potentially infectious viral material was present in the clusters. Indeed, scanning electron microscopy (SEM) and immunogold staining of HIV-1 Env glycoprotein (gp120) unveiled aggregates of Env+ viral particles (Fig. 1D). Transmission electron microscopy (TEM) unambiguously showed the viral material to be heterogeneous assemblies of enveloped viral particles, some of them appearing as empty vesicles but most of them displaying a classical dense-core morphology of mature viral particles (Fig. 1E, arrowheads). The clusters of HIV-1 virions were surrounded by electron-dense material (Fig. 1E, arrow) morphologically reminiscent of the "cocoon" of ECM components previously described for biofilm-like HTLV-1 assemblies (Pais-Correia et al., 2010).

\section{Membrane-bound HIV-1 colonies are embedded within a virally-induced ECM-rich network}

We next examined ECM components forming HIV-1 viral clusters at the T cell surface. Confocal microscopy of infected T cells revealed HIV-1 extracellular aggregates to be especially enriched in 
both collagen and agrin (Figure 2A-B; Supplementary Fig. 3A-B). Tetherin, intermingled with viral aggregates and at their contact site with the plasma membrane (Fig. 2C), was also identified. Depending on the cell type and on the virus used, collagen, agrin and tetherin accumulated in 49 to $69 \%, 47$ to $65 \%$ and 49 to $82 \%$ of HIV-1 extracellular assemblies, respectively (Fig. 2D). We observed a strong correlation between the size of HIV-1 clusters and their enrichment in tetherin, collagen and agrin (Fig. 2E), suggesting a crucial role of these ECM components in cell-surface retention and clustering of viral particles. Infected CD4+ T cells, including primary T cells, had higher collagen surface expression (Fig. 2F), supporting that HIV-1 infection triggered an increase in collagen synthesis by CD4+ T lymphocytes as previously reported with other cell types (Smith et al., 2010; Tuyama et al., 2010; Vigneault et al., 2011). Agrin was reorganized at surface of infected T cells to accumulate in the HIV-1 clusters (Fig. 2B), while its production was globally unaffected (Fig. 2G). Broader characterization of other ECM components by immunofluorescence showed that HIV-1 extracellular clusters were also enriched in $\alpha$-dystroglycan/cranin, a glycoprotein displaying agrinbinding capacities (Zhang et al., 2006), and in syndecan-4, a heparan sulfate proteoglycan upregulated upon HIV-1 infection and previously reported to bind HIV-1 virions (Supplementary Fig. 3C) (Bobardt et al., 2003; Vigneault et al., 2011). In contrast, syndecan-3, a dendritic-cell-specific attachment receptor for HIV-1 (de Witte et al., 2007) was clearly excluded from HIV-1 clusters (Supplementary Fig. 3D). Thus, HIV-1-infected $\mathrm{T}$ cells produce and retain at their surface extracellular aggregates of viral particles specifically enriched in ECM proteins such as collagen and agrin.

\section{T cells from HIV-1-infected individuals produce ECM-enriched viral particle clusters}

We then assessed the formation of cell-membrane-bound HIV-1 clusters by CD4+ T lymphocytes from six HIV-1-infected individuals with detectable viremia. About $50 \%$ of infected CD4+ T cells detected ex vivo carried extracellular CAp24+ and MAp17+ viral clusters at their surface (Fig. 3A \&

Table 1). Structured illumination microscopy (SIM) confirmed that HIV-1 extracellular aggregates from infected patients were enriched in both collagen and agrin (Fig. 3B). Similar results were 
obtained with CD4+T lymphocytes sorted from PBMC of all HIV-infected individuals analyzed, but not with samples from HIV-negative persons (Fig. 3C). We then performed correlative light confocal/electron microscopy (CL/EM) combined with immunogold labeling of $\mathrm{T}$ cells from HIV-1infected patients. Both conventional and focused ion beam (FIB)-scanning electron microscopy (SEM) showed membrane-bound HIV-1 viral assemblies that stained positive for collagen in fluorescence, and for agrin and HIV-1 Env in both fluorescence and immunogold labeling (Fig. 3C-D). CL/FIB SEM confirmed the 3D localization of agrin and HIV-1 Env immunogold labeling along dense-core viral particle clusters (Fig. 3D). These results strongly suggest that ECM-enriched HIV-1 clusters are produced in vivo (in infected individuals) and can be relevant to the pathophysiology of HIV-1 infection.

\section{HIV-1 regulates the formation of membrane-bound HIV-1 clusters}

We then investigated the role of viral proteins in the regulation of ECM-embedded HIV-1 clusters. We particularly focused our study on the viral glycoprotein HIV-1 Env, with well-known heparan sulfatebinding properties (e.g. (Alfsen et al., 2005)), and on the viral accessory proteins Vpu and Nef. Both Vpu and Nef modulate intracellular trafficking and secretory pathways and, in the case of Vpu, favor the release of viral particles by reducing tetherin exposure at the cell surface (Strebel, 2013; Sugden et al., 2016). Primary CD4+ T cells were infected with the pseudotyped wild-type virus NL4-3 (WT) or the same virus lacking viral protein Vpu, Nef or Env (Supplementary Fig. 4). Formation of membrane-associated HIV-1 assemblies was analyzed by confocal microscopy (Fig. 4A insets) and by SIM (Fig. 4A). In the absence of Nef, HIV-1 CAp24+ and MAp17+ clusters appeared significantly less compact than with the WT virus, in agreement with a 2-fold decrease in total extracellular CAp24 intensity per cell (Fig. 4B-C). In contrast, the absence of Vpu led to the formation of larger and more compact extracellular CAp24 ${ }^{+}$aggregates, resulting in a 3-fold increase in membrane-bound CAp24 intensity per cell as compared to WT infection (Fig. 4B-C), consistent with the role of Vpu in viral particle release from the cell surface (Neil et al., 2008; Van Damme et al., 2008). Most markedly, the absence of Env led to the formation of few very, if any, small CAp24 ${ }^{+}$aggregates per cell (Fig. 4A); the fluorescence intensity of CAp24 spots fell below the specific detection limit of our quantification 
procedure $($ Fig. 4B; N.D. $=$ non detectable). Thus, the formation of ECM-embedded virus aggregates at the cell surface is dependent on HIV-1 Env and is regulated by Vpu and Nef, each of which modulates, in opposite ways, the quantity and architecture of HIV-1 clusters at the cell surface.

\section{HIV-1-induced collagen determines architecture and infectivity of membrane-bound HIV-1 clusters}

We then analyzed the role played by the different components of membrane-bound HIV-1 clusters in cell-associated infectivity. We first assessed the contribution of tetherin by using a previously described tetherin shRNA CEM T cell line (Casartelli et al., 2010) (Supplementary Fig. 5). CAp24+ extracellular viral clusters were found in $68 \%$ of control shRNA CEM cells infected with HIV-1, which was comparable to other T cells (Table 1). $70 \%$ of clusters had detectable tetherin contents (Supplementary Fig. 5A, left), and both tetherin-negative and tetherin-positive HIV-1 assemblies accumulated collagen (Supplementary Fig. 5B). Tetherin knock-down did not significantly impact either membrane-bound HIV-1 cluster formation (63\% versus $68 \%$ of HIV-1-producing cells; Supplementary Fig. 5A) or HIV-1 spread in our T cell-based assay (Supplementary Fig. 5C). Aggregation of extracellular CAp24+ was similar in tetherin and control shRNA conditions (Supplementary Fig. 5D), although some slight changes in the organization of mature viral particles (MAp17+) at the cell surface were frequently observed by SIM in shRNA conditions (Supplementary

Fig. 5E). This indicated that tetherin present in HIV-1 clusters is not strictly required for their formation, further suggesting that other components are playing this role.

We then assessed the role of virus-induced collagen on cell-associated infectivity by subjecting HIV-1-producing cells (ACH2) to collagenase digestion. Clostridium collagenase D (CollD) affected neither cell viability (Supplementary Fig. 6A) nor the infectivity of viral particles released in the culture supernatant (Supplementary Fig. 6B). Notably, CollD digestion reduced cellassociated infectivity by up to $55 \%$ (Fig. 5A, right), further supporting the participation of collagen in HIV-1 spread. However, CollD digestion did not result in efficient detachment of cell-associated viral material, with a maximal reduction in total CAp24+ material of 15\% (Fig. 5A, left). Contrary to what was observed after mechanical washes (Supplementary Fig. 6C), cell-associated infectivity did not 
correlate with the quantity of cell-associated material upon CollD treatment, suggesting that collagen might not only play a role in cell surface retention. We therefore examined whether CollD modified the architecture of HIV-1 clusters and/or viral particle distribution at the cell surface. Confocal imaging of HIV-1-producing T cells revealed that CollD digestion triggered a complete reorganization of HIV-1 clusters, leading to a dotted pattern of small viral aggregates scattered over the surface of infected T cells (Fig. 5B). These viral clusters were significantly smaller and highly homogeneous in size as compared to HIV-1 clusters exposed at the surface of untreated cells or at the surface of the remaining MAp17+ fraction of mechanically washed cells (Fig. 5C). Thus, collagen present within surface-bound HIV-1 clusters makes a key contribution to the efficiency of HIV-1 transmission between $\mathrm{T}$ cells, by mediating the clustering and specific spatial organization of viral particles at the cell surface.

\section{ECM-enriched HIV-1 clusters enable the "en bloc" spread of HIV-1 between cells}

We then monitored the fate of membrane-bound HIV-1 clusters and associated ECM components during cell-to-cell HIV-1 transfer. Confocal and SIM imaging of virological synapses (VS) between $\mathrm{ACH} 2$ cells and target $\mathrm{CEM} \mathrm{T}$ cells revealed that membrane-associated HIV-1 assemblies were transferred at the VS and to non-infected target $\mathrm{T}$ cells as cohesive entities, i.e. clusters of HIV-1 MAp17 $7^{+}$material embedded in agrin and collagen (Fig. 6A \& Supplementary Fig. 7A). ECMassociated HIV-1 clusters accumulated at the interface between infected and target $\mathrm{T}$ cells in 55\% of the junctions studied (Fig. 6A). Further, we observed the capture and retention of HIV-1 assemblies with ECM components at the surface of target T cells (Supplementary Fig. 7B). Transfer of ECMassociated HIV-1 colonies between T cells appeared to be quite rapid, as 5\% of target $\mathrm{T}$ cells carried HIV-1 MAp17+ collagen+ agrin+ patches after only 10 min of coculture with HIV-1-infected cells, and 17\% after 90 min (Supplementary Fig. 7B). In cultures of CD4+ T cells from HIV-1-infected patients, clusters of HIV-1 virions embedded in ECM components (collagen and agrin) were similarly observed during transfer via the VS formed between infected and non-infected lymphocytes (Fig. $\mathbf{6 B} \& \mathbf{C})$, together with evidence of capture of ECM-virus clusters by non infected T lymphocytes (Fig. 6C right \& Supplementary Fig. 7C). HIV-1 colonies embedded in ECM components are thus 
adhesive structures that enable efficient and collective transfer of HIV-1 to target cells.

We then examined whether local accumulation of HIV-1 particles at the contact site, and viral transfer, were affected when CollD-treated ACH2 cells contacted target cells. CollD treatment did not alter the formation of contacts (VS) between infected and target cells (Fig. 6D-E). However, the concentration of viral particles at the contact site was drastically reduced as compared to untreated cells (Fig. 6D, arrows). Only a few, smaller HIV-1 clusters were transferred to target cells (Fig. 6D, arrowheads \& Fig. 6F), in agreement with the observed 55\% decrease in cell-associated infectivity (Fig. 5A). Thus, collagen contained within surface-bound HIV-1 clusters provides a scaffold that supports collective and efficient transmission of HIV-1 between T cells.

\section{HIV-1 in ECM-enriched virus clusters is more infectious than is cell-free individual virion}

We then investigated the contribution of the Virus-ECM clusters (VEC) to the observed increase in the infectivity of HIV-1 during cell-cell contacts (Chen et al., 2007; Dimitrov et al., 1993; Mazurov et al., 2010). In the same assay, we measured the capacity of cell-associated HIV-1 clusters to infect T cells, by comparison with cell-free viral particles released in cell-culture supernatants (coculture with Jurkat LTR-Luc). We mechanically washed VEC-producing $\mathrm{T}$ cells, quantified by ELISA the amount of CAp24 released by the washes $(\boldsymbol{Q})$, and complemented VEC-depleted (mechanically washed) cells with an equal amount of CAp24 Q' (Q'=Q) of cell-free viruses (FV) collected from corresponding cell-culture supernatants (Fig. 7A). Complementation of MW cells with an equal amount of cell-free viruses $\left(\mathrm{MW}+\mathrm{FV}\right.$; $\left.\mathrm{Q}^{\prime}=\mathrm{Q}\right)$ significantly increased the infection of target cells (1.6-fold increase in Luc activity), but did not rescue the infectivity of $\mathrm{T}$ cells carrying VECs (2.6-fold higher infectivity as compared to NT cells) (Fig. 7B). This indicated that viral particles accumulating in VECs at the T cell surface are more infectious than their cell-free counterparts.

We then investigated whether this increased infectivity is an intrinsic property of ECMenriched HIV-1 clusters, independently of the carrier cell. Therefore, cell-surface viral material was detached from cells before analysis (see Methods). Correlative Env confocal-SEM of these samples unveiled viral aggregates of heterogeneous size, some composed of several hundred viral particles (Fig. 7C). The viral particles were organized along fibers, forming a large connective framework 
likely composed of ECM components. When normalized for the amount of CAp24 protein, HIV-1 clusters displayed a 6-fold increase in infectivity as compared to cell-free viral particles (Fig. 7D), indicating that VEC-associated viral particles are more infectious than their cell-free counterparts, and that this property does not depend on the carrier cell. Western blot analysis of the two viral particle pools showed no obvious differences in Gag or Env content or maturation (Fig. 7E). Thus, the intrinsic features of HIV-1 clusters likely result from ECM-mediated clustering or organization of viral particles rather than qualitative differences between VEC-associated and cell-free virions. Accordingly, CollD treatment of pre-adsorbed membrane-associated HIV-1 material unpacked the HIV-1 clusters and fractionated the network clustering virions (Supplementary Fig. 8A-C), with a significant 3.8-fold decrease in infectivity (Supplementary Fig. 7D). Hence, ECM components, and notably the collagen scaffold, provide HIV-1 colonies with a specific organized architecture, independently of HIV-1 retention at the surface of infected cells, contributing to the increased infectivity of ECM-associated HIV-1 pools as compared to cell-free individual virions.

\section{Spread via membrane-bound HIV-1 clusters reduces the effectiveness of antiretroviral drugs}

We then analyzed if virus-ECM cluster spread could impact the effectiveness of ArT in blocking HIV1 infection. In all co-culture conditions, the nucleoside analog reverse-transcriptase inhibitor 3TC blocked HIV-1 transmission at high concentrations (95\% inhibition at $10 \mathrm{mM}$ ), showing that 3TC inhibits all modes of HIV-1 spread. However, at suboptimal drug concentrations, the residual infectivity of VEC-producing cells remained higher than that of washed cells, complemented (W+FV) or not complemented (W), with equivalent amounts of CAp24 free virus (Fig. 8A, left).

We postulated that the increased efficiency of cell-to-cell spread and the decreased effectiveness of 3TC might be caused by the ability of the ECM-embedded HIV-1 clusters to simultaneously transfer a large number of viral particles to target cells and thereby to locally increase the multiplicity of infection (MOI). We tested this hypothesis by repeating the same type of experiment at equivalent infectivity rather than equal CAp24. Mechanically washed cells were complemented with a large excess of cell-free viral particles (Q'>>Q; range 2 to 10 depending on the experiment) in order to reach the same infectivity as that of VEC-producing cells in the absence of the drug. At any 3TC 
concentration, the residual infectivity of untreated cells and mechanically washed cells complemented with cell-free viral particles remained identical (Fig. 8A, right \& Fig. 8B). Accordingly, the relative inhibition of infection by $3 \mathrm{TC}$ was similar in non-treated and complemented cells (Fig. 8B; 45\% inhibition at $1 \mathrm{mM}$ ), showing that the reduced 3TC effectiveness on cell-to-cell transmission may be due mainly to the increased efficiency of VEC spread in the absence of drugs. Similar results were obtained with the entry inhibitor AMD3100 that targets the CXCR4 co-receptor (Supplementary Fig. 9A-B). This demonstrated that membrane-bound HIV-1 clusters locally generate a high multiplicity of infection and favor productive infection of target cells through a local quorum effect. Hence, by locally concentrating virions and enabling the simultaneous transfer of multiple viral particles per target cell, ECM-enriched HIV-1 clusters enhance transmission efficiency and decrease ArT effectiveness on HIV-1 spread.

\section{HIV-1 in ECM-virus clusters is less sensitive to neutralization by bNAbs than is cell-free individual HIV-1}

We used a similar approach to study the role of ECM-embedded HIV-1 clusters in the reported decreased sensitivity of cell-to-cell transmission to bNAbs. The potent 3BNC117 bNAb, which targets the CD4 binding site of the HIV-1 envelope spike protein gp160 (Mouquet, 2014), suppresses both viremia and viral rebound during cART interruption (Caskey et al., 2015; Scheid et al., 2016; Schoofs et al., 2016). We also used two other gp160-specific bNAbs, namely PG16 (recognizing $N$-glycan V1/V2 loops) (Walker LM, 2009), which partially blocks NL4-3 cell-free infection but not cell-to-cell transmission, and PGT121 (binding to the $\mathrm{N}$-glycan V3 loop) (Walker LM, 2011), which blocks neither mode of NL4-3 spread (Malbec et al., 2013). 3BNC117 strongly inhibited HIV-1 transmission in all co-culture conditions, at the highest concentration (up to $95 \%$ inhibition at $10 \mu \mathrm{g} / \mathrm{ml}$ ) (Fig. 8C, left panel). However, at suboptimal concentrations of 3BNC117 (below $10 \mu \mathrm{g} / \mathrm{ml}$ ), the residual infectivity of VEC-producing cells remained higher than the infectivity of mechanically washed cells, whether complemented or not with cell-free virus, indicating that VEC contribute to reducing the effectiveness of 3BNC117. As previously shown, PG16 and PGT121 were unable to inhibit NL4-3 
cell-to-cell transmission, even at high concentrations (Fig. 8C). PG16 only partially inhibited the effect of cell-free HIV-1, with $25 \%$ inhibition at $20 \mu \mathrm{g} / \mathrm{ml}$. Notably, 3BNC117 was also significantly less effective at inhibiting VEC versus cell-free transmission at all suboptimal concentrations (below $10 \mu \mathrm{g} / \mathrm{ml}$ ), with 25\% inhibition at respectively 0.1 and $1 \mu \mathrm{g} / \mathrm{ml}$ (Fig. 8D \& Supplementary Fig. 9B), suggesting that ECM-embedded virus clusters may not only concentrate HIV-1 but also shield viral particles from 3BNC117 neutralization. Thus, by concentrating viral particles in a protective microenvironment, virus-ECM clusters reduce the capacity of the highly potent bNAb 3BNC117 to inhibit HIV-1 transmission.

\section{DISCUSSION}

Here, we show that HIV-1 spread between T lymphocytes is predominantly due to colonies of virions physically linked together by an ECM network, the composition and architecture of whose are controlled by HIV-1. Most importantly, we provide new insights into how HIV-1 hijacks the ECM, and particularly collagen, to travel efficiently and collectively between cells in a stealthy manner, which likely participates in the seeding and maintenance of replicative sites in the host.

Although previous studies have suggested that surface-retained clusters of viruses could participate in HIV-1 cell-to-cell transmission (Hubner et al., 2009; Kieffer et al., 2017; Symeonides et al., 2015), HIV-1 spread between T lymphocytes was thought to result mainly from transmission of individual virions, locally concentrated at the viral synapse (VS) through polarized budding during contact-mediated spread (Alvarez et al., 2014; Chen, 2012; Jolly, 2010). Viral particles clustered and retained at the surface of infected $\mathrm{T}$ cells were considered to be poorly infective, owing to residual tetherin-mediated encystment observed in the absence of Vpu (Casartelli et al., 2010; Neil et al., 2008; Van Damme et al., 2008). Their contribution to HIV-1 spread has not previously been specifically evaluated or properly compared to that of individual viruses released in culture supernatants. Our work identifies the HIV-1 pool contained in ECM-enriched structures as a major source of infectivity. The major contribution of ECM-embedded viral colonies to spread does not, however, exclude release and 
spread of individual viral particles, including at the VS. The relative contribution of each mode of spreading most probably depends on the time course of the infection and on the architecture of the organ in which HIV-1 infection takes place. Importantly, our work reveals that part of the HIV-1 progeny travels collectively between cells. The recent discovery of biofilm-like HTLV-1 clusters (Pais-Correia et al., 2010) and of vesicles containing multiple infectious enteroviruses (Chen et al., 2015) further supports the concept that viruses have developed sophisticated strategies to bundle virions originating from a single infected cell into extracellular infectious structures that promote their collective transport, most probably contributing to successful infectious propagation in vivo. This may contribute to the multicopy and micro-compartmentalized infection observed in lymph nodes (Law et al., 2016a) and provide selective advantages in terms of replication kinetics and genetic diversity compared to spread of independent viral particles (Boulle et al., 2016; Sanjuan, 2017). ECM-enriched HIV-1 clusters physically hold together newly formed virions at the surface of infected cells, and these virions are subsequently transferred upon interaction with uninfected cells, at the VS or via thin membrane extensions. These infectious structures are likely to be relevant in vivo, as suggested by the production and transmission ex vivo of ECM-embedded HIV-1 clusters between CD4+ T cells isolated from all HIV-infected individuals tested in our study. Our data also demonstrate that HIV-1 spread via ECM-virus pools confers a fitness benefit compared to individual viral particle and increases the ability of HIV-1 to spread under adverse conditions. We show that the increased infectivity associated with ECM-associated HIV-1 assemblies is mainly due to a mass effect: "en bloc" transmission of virus-ECM clusters locally increases the MOI and favors infection of target cells through a quorum effect. This increased infectivity reduces the apparent sensitivity, at suboptimal doses, of cell-to-cell transmission to the effects of antiretroviral drugs (3TC and AMD3100) and to neutralization by the potent bNAb 3BNC117. In addition, clustering of HIV-1 within ECM appears to shelter viral particles from recognition at antibody concentrations sufficient to neutralize isolated viral particles. Highly glycosylated ECM proteins embedding HIV-1 clusters may limit the accessibility of anti-Env neutralizing antibodies to viral particles and complement the protective effect of the HIV-1 Env glycosylated canopy. This combination of properties makes ECM-embedded viral particle clusters an ideal mechanism for HIV-1 spread and persistence in the host, potentially even during therapy. 
Whether HIV-1 spread in vivo involves ECM-embedded viral particle colonies (or fragments) remains to be investigated. We show that the composition and the architecture of ECM-enriched viral particle clusters provide an optimal scaffold that promotes HIV-1 infection independently of the producing cell. Intrinsically, ECM-associated viral particle clusters are substantially more infectious than cell-free virions, an attribute at least partially due to the aggregative properties conferred by collagen. The strong adhesiveness of ECM-enriched HIV-1 clusters, and fragments, enables their efficient capture not only by target $\mathrm{T}$ cells but also by other surfaces (e.g. glass coverslips coated with polylysin or fibronectin), strongly suggesting that they could be easily released and captured by surrounding structures or cells in vivo. Indeed, transmission electron microscopy (TEM) studies of biopsies from non-treated HIV-infected patients showed the existence of clusters of mature HIV particles together with isolated viruses in lymph nodes and in GALT (Orenstein, 2008). Recent liveimaging and CryoTEM studies of humanized mouse models showed hundreds to thousands of fully budded virions accumulating in pools together with coiled fibrils of collagen surrounding infected cells (Kieffer et al., 2017). Deposits of HIV-1 clusters strongly reminiscent of VEC fragments along the track of infected $\mathrm{T}$ cells in lymph nodes were also observed, together with evidence of direct and indirect transmission via such cell-free pools of virus (Ladinsky et al., 2014; Murooka et al., 2012; Sewald et al., 2015; Symeonides et al., 2014).

Our work also provides new insights into how HIV-1 regulates viral particle clustering and cellsurface retention, thereby controlling infectivity and mode of spread. Apart from tetherin, the action of which is partially counteracted by Vpu during HIV-1 infection (for reviews, see (Martin-Serrano and Neil, 2011; Neil, 2013), the mechanisms regulating these processes have never been fully investigated. Our data show that viral particle clustering and cell-surface retention result from the complex interplay between viral proteins including $\mathrm{Vpu}$, Nef and Env, and several cellular factors. Our work highlights the crucial contribution of ECM components to these processes, broadening our vision of the role of the ECM in HIV-1 dissemination. In particular, we uncovered a novel role of collagen in HIV-1 spread. The main known role of collagen in the pathophysiology of HIV-1 infection was in fibrotic damage induced by collagen deposition in lymphatic tissues, limiting CD4+ T cell repopulation and 
impairing the immune function of secondary lymphoid organs (Beghini et al., 2015; Estes, 2009; Schacker et al., 2002; Zeng et al., 2011). We now provide evidence that (i) HIV-1 infection of T lymphocytes increases collagen secretion/production, possibly through a Tat-dependent mechanism that has been reported in other cell types (McArthur et al., 2001; Taylor et al., 1992; Tuyama et al., 2010); (ii) virally induced collagen confers a specific organized architecture on surface-bound HIV-1 colonies, creating threads that connect virions with one another and thus forming a $2 \mathrm{D}$ and $3 \mathrm{D}$ meshwork; (iii) the collagen scaffolding enables collective transmission of part of the viral progeny and increases HIV-1 infectivity. HIV-1 adjusts cohesiveness and cell-surface retention of viral particles colonies by fine-tuning the composition of ECM-virus clusters in tetherin but also in ECM molecules such as collagen, thereby controlling viral infectivity and the mode of spread. The specific use of some ECM components, such as collagen, by HIV-1 to collectively traffic between cells may have additional significant implications for viral pathogenesis. ECM components might also provide a protective microenvironment that preserves viral particles, ensuring optimal maturation. Isolated cellfree HIV-1 has a very short lifespan (0.3 days for plasma virions (Perelson et al., 1996)), and ECM sheltering would prolong its infectivity, as already reported for some syndecans (Bobardt et al., 2003), which we found to accumulate in ECM-rich HIV-1 clusters. Specific ECM components have the potential to provide VEC with additional features enhancing HIV-1 capture and infectivity, potentially increasing the panel of target cells. This includes alternative entry pathways such as endocytosis of ECM-HIV-1 clusters prior to viral envelope fusion (Dale et al., 2011), which ultimately seems to occur through the canonical pathway (Env/CD4-dependent and CXCR4-dependent fusion process in the case of NL-4.3). ECM-embedded HIV-1 colonies could also be grabbed by non-permissive cells such as DCs, thus disseminating HIV-1 infection in vivo, and contribute to amplifying the infection in the host (Cameron et al., 1992; Dahabieh et al., 2015; Sewald et al., 2015). ECM components of HIV1 clusters, and particularly collagen, may also undermine the establishment of efficient antiviral immune responses and assist with viral escape.

In summary, our work identifies ECM-embedded HIV-1 clusters as novel, highly infectious 
extracellular structures that concentrate, shelter and disseminate colonies of viral particles. Formation of Virus-ECM clusters appears to be a common strategy employed by human retroviruses for efficient, collective and protected spread of virions originating from the same infected cell. Notably, some components that are specifically and consistently enriched in membrane-bound HIV-1 clusters are also present in HTLV-1 clusters (Pais-Correia et al., 2010), suggesting that these two human retroviruses hijack similar cellular pathways and processes for collective travel between cells. Our study provides a rationale for developing novel strategies to limit retroviral spread by targeting components of membrane-associated HIV-1 clusters, including ECM components such as collagen. This mode of transmission, which promotes infection and ensures viral replication despite immune responses and therapies, may not only contribute to successful propagation in vivo but also favor viral persistence and, probably, immune evasion. 


\section{METHODS}

\section{Antibodies and reagents}

Rabbit anti-HIV-1 CAp24 Ab and human Ab anti-HIV-1 gp120 2G12 were obtained through the NIH AIDS Reagent Program. Mouse mAbs to HIV-1 MAp17 (18-A), to CAp24 (25-A) and to HIV-1 gp120 (110H) were from Hybridolabs, Institut Pasteur. Note that the 18-A anti-HIV-1 MAp17 antibody detects only the cleaved matrix protein MAp17 and therefore labels only mature virus particles present at the $\mathrm{T}$ cell surface, as confirmed by colocalization between MAp17 and Env (Sup Fig 2). FITC-conjugated anti-p24 Ab KC57 was from Becton-Dickinson. Mouse IgG2a mAb to CD45 (GAP 8.3) was from ATCC and mouse anti-CD98 mAb was from R\&D Systems. Rabbit antibodies (Ab) to agrin (707T and 204) were kind gifts from Dr M. Rüegg. Rabbit polyclonal antibody to human collagens I, II, III, IV and V was from AbD Serotec. The versatile collagen probe Ace (Boerboom et al., 2007) was produced in a bacterial system using a plasmid given by Dr. M. Hook and was subsequently coupled to Alexa488 (Molecular Probes). Polycolonal mouse anti-Cranin Ab was from Chemicon. Mouse polyclonal anti-Tetherin $\mathrm{Ab}$ and rabbit anti-Syndecan 4 and anti-Galectin $3 \mathrm{Abs}$ were from Abcam. Rabbit anti-Syndecan 3 Ab was from Atlas. DAPI was from Invitrogen. FITCcoupled Abs to mouse IgG1, IgG2a and IgG2b were from Southern Biotechnology. Cy3-coupled Ab to rabbit IgG and to mouse $\operatorname{IgG} 1, \operatorname{IgG} 2 \mathrm{~b}$ and $\operatorname{IgG}$ as well as Alexa647-coupled Ab to mouse IgG2a were from Jackson Immunoresearch. Cy5-coupled $\mathrm{Ab}$ to rabbit Ig was from GE Healthcare. Alexa488-coupled Ab to fluorescein was from Life technologies. Annexin V/PI and Cell Trace Violet were from (Life technologies). 20-nm colloidal gold protein A was from the University Medical Center Utrecht, $10 \mathrm{~nm}$ colloidal gold anti-mouse IgG+IgM Ab was from British Biocell International. 3BNC117, PG16 and PGT121 bNAbs were provided by H. Mouquet. The plasmid encoding firefly Luciferase under the control of HIV-1 Long Terminal Repeat (pLTR-Luc) (Reynolds et al., 2003) was a kind gift from Dr. S. Emiliani.

\section{Cells, viruses and infections}


TZMbl reporter cells and the chronically HIV-1-infected T cell line (J1.1, ACH2 and its parental cell line CEM) were obtained through the NIH AIDS Reagent Program. CEM shControl and shTetherin were a kind gift from Dr N. Casartelli (Casartelli et al., 2010). Cells lines were cultured in RPMI-1640 (Gibco) containing 10\% FCS, $10 \mathrm{IU} / \mathrm{mL}$ penicillin and $10 \mu \mathrm{g} / \mathrm{mL}$ streptomycin and the selection agent hygromycin $(400 \mathrm{ug} / \mathrm{mL})$ or puromycin $(0.5 \mathrm{ug} / \mathrm{mL})$ when required. Expression of the HIV-1 genome in $\mathrm{J} 1.1$ and $\mathrm{ACH} 2$ cells was induced by culture in the presence of TNF- $\alpha(10 \mathrm{ng} / \mathrm{ml})$ for $48 \mathrm{~h}$ and PMA (10 ng/ml), respectively.

Peripheral blood mononuclear cells from healthy donors or from HIV-1-infected patients were isolated by Ficoll-Hypaque centrifugation. CD4+ T cells were isolated by negative selection with magnetic cell sorting (Miltenyi Biotec) and the CD4+-enriched $\mathrm{T}$ cell population was cultured in AIM-V medium complemented with $40 \mathrm{U} / \mathrm{mL}$ IL-2 (Chiron) and $5 \mathrm{ng} / \mathrm{mL}$ IL-7 (R\&D systems). Blood samples from HIV-1-infected patients were obtained in the context of the Biomedical Research Program TRANSBioHIV promoted by the French National Agency for AIDS and Hepatitis (ANRS) and approved by the Ile-de-France VII ethics committee, Hôpital de Bicêtre, Kremlin-Bicêtre (ANRS FR01 TransBioHIV - ID-RCB: 2013-A010651-44). All individuals gave their informed consent. Clinical characteristics of the study subjects are shown in Table 2.

Primary CD4 $+\mathrm{T}$ cells were infected with laboratory adapted strains (HIV-1 BaL (R5) and NL4.3 (X4)) or primary isolates, (HIV-1 132W (R5), subtype E; DH12 (dual tropic) and BX08 (R5), subtype B) by spinoculation and used for further experiments after 3 to 5 days, when the infection rate reached $20 \%$ to $45 \%$. Primary CD4+ T cells were infected with VSV-G-pseudotyped NL4-3 virus wildtype (WT) or lacking viral proteins Vpu, Nef or Env, in order to reach comparable levels of productive infection on day 3 post-infection $(20-50 \%$ of CAp24+ cells; Sup Fig 4) before the occurrence of major virus-induced cytopathic effects (Thoulouze et al., 2006).

\section{Mechanical washes and collagenase $D$ and subtilisin treatment of infected cells}

HIV-1-infected cells were left unwashed, rinsed once to remove virions loosely adhering to the surface of the cells, or submitted to one to four rounds of extensive pipetting followed by a rinse in 
RPMI-1640 serum-containing medium. Alternatively, infected cells were treated with Subtilisin (5 $\mathrm{mg} / \mathrm{mL}$, Sigma-Aldrich) or Collagenase D (2 to $10 \mathrm{mg} / \mathrm{mL}$, Sigma-Aldrich) at $37^{\circ} \mathrm{C}$ in serumcontaining medium, for $5 \mathrm{~min}$ and $12 \mathrm{~h}$ respectively. Subtilisin treatment was stopped by adding an excess of Protease Inhibitor (Roche). Cells were gently rinsed three times in order to remove contaminating enzymes. Cells were then processed for immunofluorescence analysis, flow cytometry and coculture with a reporter cell line. Viral antigens were detected in cell culture supernatants or detachment supernatants by Gag p24 ELISA according to the manufacturer's instructions (Zeptometrix). When indicated, mechanically washed cells (W) were complemented with Free Virus (FV) collected from cell culture supernatants. The amount of p24 added corresponded to 3 to 5 times the amount of p24 detached from the mechanically washed cells, as assessed by p24 ELISA. Cell-free viral particles released in culture supernatants and cell-surface viral material detached by mechanical washes were first clarified by a short centrifugation step (400g for $10 \mathrm{~min}$ ) and concentrated by ultracentrifugation (2000g for $10 \mathrm{~min}$ ) before analysis by CAp24 ELISA and infectivity assay. An additional ultracentrifugation step (2000g for $2 \mathrm{~h}$ ) was performed before analysis by western blotting. Alternatively, membrane-bound HIV-1 material was isolated from HIV-1 infected cells through transient adhesion to polylysin-coated coverslips, and the cells were subsequently detached by several rinses with PBS supplemented with EDTA.

\section{Treatment with antiretroviral drugs and neutralizing antibodies}

Luciferase reporter $\mathrm{T}$ cells were preincubated for $1 \mathrm{~h}$ with increasing concentrations of antiretroviral drug (ArT: 3TC and raltegravir) prior to coculture with HIV-1-infected cells in the presence of ArT. Conversely, HIV-1-infected cells were preincubated for $1 \mathrm{~h}$ with increasing bNAb concentrations prior to coculture with the luciferase reporter $\mathrm{T}$ cell line in the presence of bNAbs.

\section{Flow cytometry}


Cells were fixed with $4 \%$ paraformaldehyde for 10 min at $25^{\circ} \mathrm{C}$, followed by Gag CAp24 and MAp17 staining as previously described (Pais-Correia et al., 2010) using KC57-FITC (BectonDickinson) and 18-A (Hybridolabs, Pasteur) respectively. Cells were analyzed on a BD Bioscience FacsCalibur.

\section{Luciferase reporter gene assay}

To assess HIV-1 infection of target cells, we generated a luciferase reporter Jurkat cell line. Jurkat J77cl20 cells were stably transfected with the plasmid pLTR-Luc (Reynolds et al., 2003) as previously described (Pais-Correia et al., 2010). Luciferase reporter cells were cocultured, in 96-cell roundbottom plates, with HIV-1-infected cells at a cell ratio of 1:1 and 3:1 for infected cell lines and primary infected $\mathrm{CD}^{+} \mathrm{T}$ cells, respectively. After 18 or $30 \mathrm{~h}$ respectively, luciferase activity was quantified with the Promega luciferase kit and read in a TR717 microplate luminometer (Berthold Technologies).

\section{Adhesion assay}

Cells were loaded with CFSE (Invitrogen) and incubated for $40 \mathrm{~min}$ in wells coated with fibronectin (R\&D systems). After several washes, adhering cells were lysed and fluorescence was measured with a Tecan fluorimeter.

\section{Immunofluorescence, confocal microscopy and structured illumination microscopy (SIM)}

Immunofluorescence experiments were performed as previously described (Pais-Correia et al., 2010). Cells were fixed in $4 \%$ paraformaldehyde for $15 \mathrm{~min}$, rinsed with PBS, and treated with $50 \mathrm{mM}$ $\mathrm{NH} 4 \mathrm{Cl}$ in PBS for 10 min to quench aldehyde groups. Surface staining (for example, CD98 or CD45) was performed in the absence of detergent. Intracellular protein and Gag staining was performed by incubating fixed cells in solutions containing $0.05 \%$ saponin. For collagen labeling, living cells were preincubated with the collagen probe Ace-Al488 $(0.5 \mu \mathrm{M})$ for $12 \mathrm{~h}$ in serum-containing medium, and 
non-fixed probe was washed 3 times with medium containing 10\% FCS prior to 4\% PFA fixation and further immunostaining. Alternatively (Sup Fig. 2), cells were immunostained after fixation, using anti-collagen Abs, as previously reported (Pais-Correia et al., 2010). For imaging of ECM-associated HIV-1 cluster transfer at the VS, HIV-infected T cells were prestained with the Ace collagen probe and cocultured at a ratio of 1:1 with target non-infected CEM cells pre-loaded with CellTrace Violet according to the manufacturer's instructions (Invitrogen). Cocultures were then fixed in an equal volume of $8 \%$ PFA at 10, 30 and 90 min before immunostaining. Confocal images were obtained with an LSM 700 microscope (Carl Zeiss) with a $63 \times$ objective. $Z$ stack optical sections were acquired at $0.2-\mu \mathrm{m}$ depth increments, and green and red laser excitations were intercalated to minimize cross-talk between the acquired fluorescence channels. Structured illumination microscopy used a Zeiss LSM780 ELYRA system with a $63 \times$ objective.

Confocal image post-treatment. Complete image stack deconvolution was performed with Huygens Essential (version 3.0, Scientific Volume Imaging), and 3D images were generated from a maximum intensity projection of the stack.

Quantitative analysis of extracellular viral aggregates. The plasma membrane of CD4 T cells was surface labeled with anti-CD98 or anti-CD45 mAbs. Confocal images were acquired at $0.2-\mu \mathrm{m}$ increments in the z-axis. We developed image analysis tools to automatically and unbiasedly quantify viral aggregates (number of aggregates, size/intensity and spread) at the surface of cells in 3D confocal acquisitions. For this, we designed a protocol in Icy (http://icy.bioimageanalysis.org, De Chaumont et al. Nat. Methods 2012) that performs sequential image analysis. A first series of operating blocks open images sequentially in the selected folder and detect the plasma membrane (labeled with anti-CD98 or anti-CD45) and the viral antigen fluorescence signal (CAp24 or MAp17) that is significantly brighter than the background noise. The automatic detection algorithm is based on wavelet transformation of fluorescence images, statistical thresholding of wavelet coefficients and denoised image reconstruction (Olivo-Marin, 2002). We then extracted each individual spot (viral particle aggregate) and measured its intensity and size. We then designed a specific analysis block (viral spread analysis) to analyze the distribution of viral aggregates at the cell surface. In this block, we first estimated the coordinates of 
the center of the cell by computing the barycenter of membrane spot coordinates. We then computed the spherical coordinates (radius, polar and azimuth angles) of viral spots, the origin being taken at the cell's center. To estimate the spread of viral aggregates around the cell, we used a greedy algorithm where we first chose the brightest (or biggest spot). Then the second spot was selected such that it minimized the ratio between the angle amplitude and total intensity (size) of the selected spots. The algorithm stops when the intensity (size) of selected aggregate spot reaches $\mathrm{x} \%$ (user-defined parameter, we used $80 \%$ ) of the total intensity (size) of spots covering the cell membrane. The protocol (Analysis of viral aggregates at the cell membrane) is publicly available on the Icy website (http://icy.bioimageanalysis.org/protocol/list).

Quantitative analysis of viral particle accumulation at the VS. Confocal images were acquired at $0.2-\mu \mathrm{m}$ increments in the z-axis. Image analysis and quantification were done using Icy software. Two regions of interest were drawn, one around the entire infected cell and one restricted to the contact area with the target cell (VS); for each optical slice, the fluorescence intensity was measured for each region. The percentage of mature viral particles (MAp17+) located within the contact area was calculated as the ratio between the total intensities inside the smaller (contact) and larger (cellular) regions.

\section{Correlative Confocal/Scanning Electron Microscopy (CL/SEM) and Focused Ion Beam- Scanning Electron Microscopy (CL/FIB-SEM)}

Live HIV-1-infected cells (ACH2 cells or CD4+ T lymphocytes from HIV-1-infected patients) were labeled with the collagen probe Ace-Alexa488 prior to being fixed (4\% PFA) on alphanumerically coded, grid-patterned glass (MatTek dishes) $\left(10^{6}\right.$ cells/coverslip). Surface staining was then performed with saturating concentrations of primary antibodies targeting HIV-1 Env $(110 \mathrm{H})$ and agrin, followed by secondary anti-mouse IgG1-Cy3 and anti-mouse coupled to $10 \mathrm{~nm}$ gold to detect Env, and antirabbit-Cy5 and protein A gold $20 \mathrm{~nm}$ to detect agrin. Cells were first imaged by confocal microscopy as described above. For further analysis by SEM, samples were then fixed by immersion in $2.5 \%$ glutaraldehyde, and post-fixed with $1 \% \mathrm{OsO}_{4}$, dehydrated through an increasing graded ethanol series 
and subjected to critical point drying with carbon dioxide as transitional medium. The glass coverslips were mounted on a specimen stub using colloidal silver paint (Electron Microscopy Sciences) and sputter-coated with 2-nm carbon nanoparticles. SEM imaging was carried out with a ZEISS Auriga Crossbeam system (Carl Zeiss NTS) using a secondary electron (SE2) detector. Immunogold labeling was detected by a back-scattered electron detector (YAG) on a Jeol JSM 6700F microscope with a field emission gun operating at $5 \mathrm{kV}$. For FIB-SEM, cells were then processed using a procedure adapted from the OTO fixation protocol (Seligman et al., 1966). Briefly, cells were first fixed by immersion in $2.5 \%$ glutaraldehyde and then subjected to two-step post-fixation treatment using a mix of $1 \% \mathrm{OsO}_{4}$ with $1.5 \% \mathrm{~K}_{4} \mathrm{Fe}(\mathrm{CN})_{6}$ (potassium ferrocyanide - reduced osmium), followed by $1 \%$ tannic acid in order to increase membrane contrast, and an additional post-fixation step in $1 \% \mathrm{OsO}_{4}$. Samples were then dehydrated through an increasing graded ethanol series and embedded in epoxy resin (Electron Microscopy Sciences) at $60^{\circ} \mathrm{C}$ for $48 \mathrm{~h}$. The embedded resin block was mounted on a specimen stub using colloidal silver paint (Electron Microscopy Sciences) and sputter-coated with 200-nm gold/palladium. Focused ion beam milling and SEM imaging were carried out with a ZEISS Auriga Crossbeam system (Carl Zeiss NTS) equipped with Atlas3D software (Fibics Inc., Ottawa) (Heymann et al., 2009; Murphy et al., 2011). A focused ion beam (30 kV, $500 \mathrm{pA})$ removed serial slices (thickness $10 \mathrm{~nm}$ ). The scanning electron beam was used to record images at pixel sizes of $5 \mathrm{~nm}$ in the xy plane. The SEM images were recorded using an energy selective back-scattered electron (ESB) detector. Individual 2D images were merged, cropped, and aligned using customized scripts based on the image processing programs ImageJ (Girish and Vijayalakshmi, 2004) and ICY (de Chaumont et al., 2012). Output images were then loaded into the Amira 5.0.1 (Visage Imaging, Berlin, Germany) software package. Structures of interest were manually segmented and reconstructed.

\section{Transmission electron microscopy}

HIV-1 genome expression was induced in J1.1 T cells with TNF- $\alpha(10 \mathrm{ng} / \mathrm{ml}$ for $48 \mathrm{~h})$. Cells were fixed with $2 \%$ glutaraldehyde in $0.1 \mathrm{M}$ Hepes, $\mathrm{pH} 7.2$ for two hours at RT. Cells were then pelleted and washed once with PBS. The cells were taken up into cellulose capillary tubes and highpressure-frozen with an HPM 010 (Abra Fluid, Widnau, Switzerland) as previously described 
(Hohenberg et al., 1994)(Hohenberg et al., 1994). Freeze substitution was done in dry acetone containing 2\% osmium tetroxide (Merck, Darmstadt, Germany) and 2\% water with an AFS (Leica microsystems, Vienna, Austria). After bringing the cells to RT they were washed in acetone and gradually infiltrated with epoxy resin (Agar Scientific, Stanstad, Great Britain). Thin sections were prepared with a Leica Ultracut UCT (Leica microsystems, Vienna, Austria) and stained with 4\% aqueous uranylacetate and Reynold's lead citrate. Images were acquired with a JEOL 1010 microscope operated at $80 \mathrm{kV}$ and equipped with a Keenview camera (Softimaging).

Statistical analysis. Depending on the experiment/quantification, the Mann-Whitney nonparametric test or Spearman correlation test was implemented with Prism software (GraphPad).

\section{LEGENDS}

Figure 1. Infectivity of HIV-1-infected T cells is mostly due to membrane-bound clusters of virions.

A-B: $\mathrm{T}$ cells chronically infected by HIV-1 (ACH2, A) or primary T cells infected in vitro with NL4-3 (B) were left non treated (NT), washed once, or subjected to gradual mechanical washes (extensive pipetting) (Mechanical wash 1-3). Left: Flow cytometric quantification of cell-associated CAp24. MFI: Mean Fluorescence Intensity. Right: Cell-associated infectivity: luciferase assay after $18 \mathrm{~h}$ of coculture with LTR-Luc reporter cells. Means + SEM from respectively eleven (A) and three (B) independent experiments. p values are calculated versus NT (Mann-Whitney test).

C: Confocal fluorescence imaging of HIV-1-infected T cells showing aggregates of mature HIV-1 material (MAp17) tightly bound to the plasma membrane (PM, CD45 labeling). Upper panel: ACH2 cells, Lower panel: primary T cells infected in vitro with NL4-3, scale bars: $5 \mu \mathrm{m}$.

D: Scanning Electron Micrographs of HIV-1 clusters bound to the surface of HIV-1-infected T cells (J1.1 T cells chronically infected by HIV-1). Extracellular aggregates of 100-nm spherical viral particles are stained positive for anti-Env immunogold. Scale bar: $5 \mu \mathrm{m}$, Insets: $500 \mathrm{~nm}$. 
E: Transmission Electron Micrograph of HIV-1 clusters bound to the surface of infected T cells (J1.1). Aggregates of 100-nm dense-core mature viral particles (arrowheads) are embedded in an electrondense material (arrow). Scale bar: $100 \mathrm{~nm}$.

\section{Figure 2. Membrane-bound HIV-1 colonies are embedded within a virally-induced ECM-rich} network

A-B: Confocal fluorescence imaging of $\mathrm{ACH} 2$ cells, showing collagen (A) and agrin (B) enriched in extracellular mature viral aggregates (MAp17+) at their surface (PM, CD98 labeling), scale bars: 5 $\mu \mathrm{m}$.

C: Confocal fluorescence imaging of $\mathrm{ACH} 2$ cells, showing simultaneous collagen and tetherin enrichment in viral aggregates (HIV-1 Env gp120+) at the surface of an infected T cell. Plasma membrane in yellow (dashed line). Scale bar: $2 \mu \mathrm{m}$.

D: Quantification of the fraction of HIV-1 extracellular clusters (MAp17+ or CAp24+) accumulating collagen (black), agrin (dark gray) and tetherin (light gray) at the surface of infected cells. Means + SEM of at least 150 cells from 3 independent experiments. na $=$ not available.

E: Quantification of tetherin, collagen and agrin content in cell-associated HIV-1 clusters (ACH2 cells). Each dot represents a cell-associated HIV-1 cluster (CAp24+ or MAp17+) plotted according to its volume $\left(\mu \mathrm{m}^{3}\right)$ and its fluorescence intensity value in tetherin, collagen or agrin. Spearman $\mathrm{R}^{2}$ coefficients and corresponding $\mathrm{p}$ values are indicated. This experiment is representative of at least three experiments.

F-G: Quantification of cell-surface collagen $(\mathbf{F})$ and agrin $(\mathbf{G})$ contents of HIV-1-infected cells. Primary CD4+ T cells infected in vitro with primary isolate DH12 were surface-stained for collagen and agrin. Total fluorescence intensity in infected (CAp24+ or MAp17+) and non-infected cells (CAp24- or MAp17-) was automatically quantified on confocal images. The Mann-Whitney test (p $<0.0001)$ was used for statistical analysis. Similar results were obtained with ACH2 cell line.

Figure 3. CD4+ T cells from HIV-1-infected patients produce ECM-embedded HIV-1 clusters. 
A: Confocal fluorescence imaging of a naturally infected CD4+ T cell (isolated from an HIV-1infected patient) showing aggregates of mature viral material (MAp17) tightly bound to the plasma membrane (PM, CD45 labeling).

B: Structured Illumination Microscopy (SIM) showing collagen (top panel) and agrin (bottom panel) enriched in HIV-1 aggregates (CAp24+ or Map17+) on the surface of the plasma membrane (PM, CD45 labeling). Scale bar: $5 \mu \mathrm{m}$, inset: $1 \mu \mathrm{m}$.

C: Correlative Confocal-Scanning Electron Microscopy of an infected CD4+ T cell isolated from an HIV-1-infected patient. Note the viral particle cluster enriched in ECM (Arrow). Top left panel: confocal fluorescence images showing HIV-1 Env, collagen, and agrin immunostaining and the transmission image. Scale bar: $5 \mu \mathrm{m}$. bottom left panel: Scanning Electron Micrograph of the same cell. Scale bar: $2 \mu \mathrm{m}$. Right top panel: enlargement. Scale bar: $300 \mathrm{~nm}$. Bottom right panel: same enlargement showing HIV-1 Env (10 nm, red arrowheads) and agrin (20 nm, white arrowhead) immunogold labeling.

E: Correlative Confocal-Focused Ion Beam Scanning Electron Microscopy (FIB-SEM) of an infected CD4+ T cell isolated from an HIV-1-infected patient. Note the viral particle cluster enriched in ECM (Arrow). Top left panel: confocal fluorescence image showing HIV-1 Env, collagen, and agrin immunostaining and the transmission image. Other panels: FIB-SEM of the same cell. Single thin section (bottom left \& upper right) and projection of three thin sections (3D; bottom right) displaying dense-core viral particles (arrow) stained positive for HIV-1 Env (10 nm, red arrowhead) and surrounded by agrin $(20 \mathrm{~nm}$, white arrowhead). Scale bars: $500 \mathrm{~nm}$.

\section{Figure 4. HIV-1 regulates formation and architecture of membrane-bound HIV-1 clusters.}

Primary CD4+ T cells were infected with VSV-G-pseudotyped NL4-3 virus, wildtype (WT) or deficient in viral proteins $\mathrm{Vpu}$, Nef or Env, in order to reach comparable levels of productive infection on day 3 post-infection (25-50\% of CAp24+ cells; sup Fig 4) before the occurrence of major virus-induced cytopathic effects (Thoulouze et al., 2006), and were then immunostained. 
A: Structured Illumination Microscopy showing HIV-1 MA-p17 distribution at the surface of infected cells. Inset: Confocal micrograph of the same cell showing membrane-bound HIV-1 clusters (MAp17) on the surface of the plasma membrane (PM: CD45 labeling) Scale bars: $5 \mu \mathrm{m}$.

B: Automated quantification of the mean intensity (top) and the number (bottom) of HIV-1 extracellular clusters per infected cell ( $\mathrm{N}=15$ to 20 cells).

C: Automated quantification of the mean intensity (top) and degree of compaction (= Intensity/volume; bottom) of each HIV-1 extracellular cluster.

\section{Figure 5. Virally induced collagen influences architecture and infectivity of membrane-bound HIV-1 clusters.}

HIV-1-infected T lymphocytes (ACH2) were left untreated (NT), mechanically washed (W), or treated overnight with a range of collagenase D (CollD) concentrations.

A: Left. Flow cytometric quantification of cell-associated HIV-1 (CAp24). MFI: Mean Fluorescence Intensity. Right. Cell-associated infectivity (Luc activity) after $18 \mathrm{~h}$ coculture with reporter T cells. NI $=$ Non infected. Means + SEM from three independent experiments.

B: Confocal fluorescence microscopy of untreated (NT), mechanically washed (W) and collagenase D-treated (CollD; $10 \mathrm{mg} / \mathrm{ml})$ cells. Left: 3D projections of MA-p17 fluorescence on the plasma membrane (CD45 labeling). Right-hand panels represent the density profiles of MA-p17 fluorescence. Right: Quantification of the fraction of HIV-1 producing cells with a reorganized dotty MAp17 pattern.

C: Automated quantification of HIV-1 CA-p24+ extracellular clusters at the cell surface. Top: Number (left) and distribution at the cell surface ("spherical spread"; right) of CA-p24+ clusters. Each dot represents an infected cell. Bottom: Quantification of the mean size, mean intensity and mean compaction index (intensity/volume) of CA-p24+ extracellular clusters on each cell. $\mathrm{N}=20$ cells/condition. (Mann-Whitney test). 
Figure 6. Viral particles accumulated in membrane-bound HIV-1 clusters are transferred "en bloc" to target $\mathrm{T}$ cells along with ECM components

A: Confocal fluorescence microscopy of a virus-ECM cluster transferred between an ACH2 T cell chronically infected by HIV-1 (labeled with Ace collagen probe prior to coculture) and a target T cell (CEM cells labeled with CellTrace Violet prior to coculture, * cyan). ECM-associated HIV-1 clusters stains positive for HIV-1 MAp17, collagen and agrin.

B-C: Transfer of ECM-enriched HIV-1 clusters between T cells from an HIV-1-infected patient.

B: SIM showing HIV-1 MAp17+ agrin+ clusters at the cell interface. Scale bar: $1 \mu \mathrm{m}$.

C: Scanning Electron Micrograph showing the co-transfer of viral particle clusters $\left(\mathrm{Env}^{+}, 10 \mathrm{~nm}\right)$ associated with agrin $(20 \mathrm{~nm})$ on the side of the junction. HIV-1-infected $\mathrm{T}$ lymphocyte and target $\mathrm{T}$ cell $(*)$ can be identified both by agrin immunogold labeling (homogeneous on the target $\mathrm{T}$ cell surface but concentrated in HIV-1 clusters on the infected cell) and by cell shape (plasma membrane elongations characterizing infected T lymphocytes (Nobile et al., 2010)). Scale bar: $2 \mu \mathrm{m}$. Inset: scale bar $100 \mathrm{~nm}$.

D-E: Impact of CollD treatment on HIV-1 spread via cell-cell contacts. HIV-1-infected T lymphocytes $(\mathrm{ACH} 2)$ were left untreated $(\mathrm{NT})$ or treated overnight with a range of collagenase $\mathrm{D}$ (CollD) concentrations prior coculture with CellTrace Violet-labeled CEM cells (* target cells cyan), then fixed and stained for MA-p17 (red).

D: Representative 3D projection of $\mathrm{T}$ cell conjugates (confocal microscopy). Arrows point to polarized MA-p17 staining at the intercellular junction. Arrowheads point to MA-p17+ virions transferred to the target cell. Scale bar, $5 \mu \mathrm{m}$.

E: Quantitative analysis of conjugate formation by Gag+ cells with target T cells. A total of about 300 infected cells were analyzed in each condition. The mean +/-SD of three independent experiments is shown.

F: Quantitative analysis of HIV-1 MA-p17 clustering at the cell-cell junction. The intensity of MAp17 fluorescence at the cell interface was measured. A total of 20 conjugates were analyzed in each condition. Mean +/- SEM (Mann-Whitney test). 


\section{Figure 7. HIV-1 in virus-ECM clusters is more infectious than free viral particles}

A: Schematic representation of the experimental set-up. HIV-1-producing $\mathrm{ACH} 2$ cells were left untreated (NT) or subjected to mechanical washes (W). CAp24 released by mechanical washes (Q) was measured by ELISA. Mechanically washed cells were then complemented (W+FV) with an equivalent amount ( $\left.\mathrm{Q}=\mathrm{Q}^{\prime}\right)$ of cell-free viral particles (CAp24) collected from the corresponding cell culture supernatant (SN) prior to coculture with reporter cells.

B: Infectivity of NT, W and W+FV cells (Luciferase activity). Means +/- SEM of triplicates from 12 independent experiments (Mann-Whitney test)

C: Correlative Confocal-Scanning Electron Micrograph of membrane-bound HIV-1 material from ACH2 cells adsorbed to a glass coverslip. Top left panel: confocal fluorescence image. HIV-1 Env and agrin immunostaining overlaid with the transmission image. Scale bar: $5 \mu \mathrm{m}$. Top right panel: Scanning Electron Micrograph of the same ECM-associated HIV-1 cluster. Scale bar: $2 \mu \mathrm{m}$. Left panels: enlargements showing viral particles forming a large connective framework. Immunogold HIV-1 Env $10 \mathrm{~nm}$ (red arrow); agrin $20 \mathrm{~nm}$ (blue arrow) Scale bar: $100 \mathrm{~nm}$.

D-E: Comparative analysis of membrane-bound HIV-1 clusters detached from infected cells and cellfree HIV-1 collected from corresponding cell culture supernatants.

D: Luciferase assay determining the infectivity of cell-free viral particles and detached ECMassociated viral particle clusters, normalized by the amount of CAp24 (mean +/- SEM of triplicates from 4 independent experiments).

E: Gag and Env composition by western blotting. Representative of 6 independent experiments.

\section{Figure 8. Virus-ECM clusters protect HIV-1 spread from 3TC and bNAbs}

A-D: The same experimental set-up as in Figure 7A\&B was used, except that reporter $\mathrm{T}$ cells were pre-incubated for $1 \mathrm{~h}$ with a range of 3TC concentrations prior to coculture (A-B), or that infected cells $(\mathrm{NT}, \mathrm{W}$ or $\mathrm{W}+\mathrm{FV})$ were pre-incubated for $1 \mathrm{~h}$ with bNabs $(\mathbf{C}-\mathbf{E})$. Means + SEM of 3 independent experiments (Mann-Whitney test). 
A: Residual infectivity of NT (red), W (blue) and W+FV (purple) and non infected (NI, gray) cells in the presence of a range of 3TC concentrations at equivalent CAp24 amounts (Q=Q'; left) and at equivalent infectivity in the absence of drug (Q'>>Q; right).

B: \% inhibition of HIV-1 spread by 3TC.

C-D: At equivalent infectivity in the absence of drug (Q'>>Q). (C) Residual infectivity of NT (red), $\mathrm{W}$ (blue) and W+FV (purple) and non infected (NI, gray) cells in the presence of the indicated bNAbs. (D) \% inhibition of HIV-1 spread by 3BNC117.

\section{Acknowledgements.}

The authors wish to thank the study participants for their generous contribution to research. We thank A. Salles, M. Sachse, S. Guadagnini, P. Versmisse, V. Lorin, P. Roux and A. Danckaert (Institut Pasteur) for reagents and technical expertise. We thank S. Emiliani (Institut Cochin, Paris), C. TorrentBerlioz (Institut Cochin, Paris), M. Rüegg (University of Basel, Switzerland), M. Hook and B. Russel (Texas A\&M Health Science Center, Huston) for the kind gift of expression vectors and Abs and for sharing expertise. The NIH AIDS Research and Reference Reagent Program is thankfully acknowledged for providing Abs and cell lines. This work was funded by grants from l'Agence Nationale de Recherche sur le SIDA et les hépatites (ANRS), l'Institut Pasteur (PTR-445), as well as by institutional grants from Institut Pasteur and the Centre National de la Recherche Scientifique (CNRS). CI was supported by an Allocation de Recherche du Ministère de l'Education Nationale, de la Recherche et de la Technologie and by a bourse from the Fondation pour la Recherche Médicale. MC was supported by a fellowship from AXA Research fund, AD by a fellowship from l'Institut Pasteur (PTR-445), and TL by a Roux Fellowship (Institut Pasteur). We gratefully acknowledge the financial support of the FranceBioImaging infrastructure network supported by the French National Research Agency (ANR-10-INSB-04, Investments for the future and ANR-10-LABX-62-IBEID) and the Région Ile-de-France (program DIM-Malinf). The support of E. Mottez (Center for Human Immunology, Institut Pasteur) and A.M. Rey-Cuillé (ANRS) is thankfully acknowledged. We thank B. Blondel, M. Backovic, B. Saunier and F. Bontemps and M.C. Saleh for helpful discussions and for critical reading of the manuscript. 


\section{Author's contributions.}

$\mathrm{CI}, \mathrm{MC}$ and $\mathrm{AD}$ designed and performed experiments and analysed the data. $\mathrm{PB}$ and $\mathrm{AM}$ performed electron microscopy experiments. AD performed experiments and made the patient cell collection. OL, FB and $\mathrm{KB}$ obtained viro-epidemiological data on blood patient samples, did the follow up of the patients and provided blood samples. MM-L and FT contributed with technical developments for some experiments. GP and HM contributed with reagents and discussion. TL, AD and JCOM helped for cell imaging quantification. AS-C co-supervised some aspects of the project. MIT designed the project, supervised experimental work and wrote the manuscript with input from all other authors.

Conflict of interest. The authors declare to have no financial conflict of interest.

\section{SUPPLEMENTARY MATERIAL}

\section{Supplementary Figure 1}

A: Flow cytometric quantification of cell-associated CAp24

B: Quantification (flow cytometry) of the fraction of AnnexinV ${ }^{-}{ }^{-}$viable $\mathrm{ACH} 2$ cells $24 \mathrm{~h}$ after 3 successive mechanical washes

C: Quantification of cell adhesion to fibronectin after 3 successive mechanical washes, means + SEM of three independent experiments.

D: Luciferase assay after $18 \mathrm{~h}$ of coculture of ACH2 cells with LTR-Luc reporter cells, in the presence or absence of 3TC or Subtilisin. Subtilisin treatment (Subt) of infected cells prior to coculture with reporter cells was used to control for cell surface stripping, and treatment of reporter cells with 3TC was used to control for the specificity of Luc activity to HIV-1 infection. Means + SEM from five independent experiments. P values versus non-treated cells NT (Mann-Whitney test). 
E: Left: Confocal imaging of $\mathrm{ACH} 2$ cells subjected or not to a mechanical washes. 3D projections of MA-p17 fluorescence and plasma membrane labeling of the cell (CD45). Right: Correlative decrease in cell-associated CAp24 and MAp17 material upon mechanical washes.

\section{Supplementary Figure 2}

Confocal fluorescence images of:

A: Aggregates of HIV-1 mature viral particles (MAp17, red) at the surface of $\mathrm{T}$ cells chronically infected with HIV-1 (J1.1) and primary CD4+ T cells infected in vitro with HIV-1 BaL or the primary isolate DH12 (labeling of the plasma membrane in green: CD98 in upper panel, CD45 labeling in lower panels).

B: MAp17 clusters on thin membrane extensions bridging CD4+ T cells.

C: MAp17 clusters at the surface of infected DH12 primary T cells forming a syncytium.

D: Extracellular aggregates of HIV-1 mature particles (MAp17, green) produced by T lymphocytes chronically infected with HIV-1 ACH2 are positive for HIV-1 Env immunostaining (2G12 antibody, red). NI = Non infected. Scale bars: $5 \mu \mathrm{m}$.

\section{Supplementary Figure 3}

Confocal fluorescence imaging

A: Aggregates of HIV-1 mature material (MAp17 red) at the surface of T cells chronically infected with HIV-1 J1.1 (CD98 labeling of the plasma membrane in green) accumulate collagen (immunostained with a pan anti-collagen I-IV Ab, blue). Scale bars: $5 \mu \mathrm{m}$.

B: Aggregates of HIV-1 mature material (MAp17) at the surface of a primary CD4+ T cell infected with HIV-1 primary isolate Bx08 (CD45 labeling = plasma membrane) accumulate agrin (blue). Scale bars: $5 \mu \mathrm{m}$.

C-D: ECM-associated HIV-1 clusters (MAp17 ${ }^{+}$or $\mathrm{CAp}_{2} 4^{+}$, green) at the surface of primary CD4+ T cells infected with HIV-1 primary isolates DH12 and Bx08 (CD45 = plasma membrane, grey). 
Membrane-bound HIV-1 clusters are enriched in $\alpha$-dystrogycan/cranin and syndecan 4 (red) (C). Syndecan 3 is excluded from HIV-1 clusters (D). NI = Non infected cells. Scale bars: $5 \mu \mathrm{m}$

\section{Supplementary Figure 4}

$\%$ infection of primary CD4+ T lymphocytes by VSV-pseudotyped HIV-1 NL4-3 mutants. The \% of infected cells was determined by confocal microscopy (cytoplasmic CAp24 labeling). Means + SEM of three independent experiments. P values versus non-treated cells NT (Mann-Whitney test).

\section{Supplementary Figure 5}

ShControl (shCtl) and shTetherin (shTet) CEM cells were infected in vitro with VSVG-pseudotyped NL4-3 virus and analyzed 3 days later (30\%-50\% of CAp24+ cells).

A-B: Confocal fluorescence images of ECM-enriched HIV-1 clusters produced by infected ShControl and shTetherin cells. Cells were stained for (A) tetherin (green) and HIV-1 CAp24 (red), (B) collagen (Ace probe, green), HIV-1 Env-gp120 (2G12 antibody, red) and tetherin (blue). Scale bar: $5 \mu \mathrm{m}$

C: Infectivity of shControl (shCtl) and shTetherin (shTet) CEM cells infected with HIV-1 (Luciferase assay). Means + SEM of three independent experiments.

D: Automated quantification of number of membrane-bound HIV-1 clusters per infected cell, the mean intensity and the mean degree of compaction (= mean intensity / volume) of HIV-1 extracellular clusters. Each dot represents an infected cell.

E: Structured Illumination Microscopy (SIM) showing HIV-1 MA-p17 distribution at the surface of ShControl and shTetherin T cells infected with HIV-1. Scale bar: $2 \mu \mathrm{m}$.

\section{Supplementary Figure 6}

$\mathrm{ACH} 2$ cells were treated overnight with the indicated collagenase D concentrations.

A: Fraction of viable cells measured by flow cytometry (FSC'SSC) (Thoulouze et al., 1997). 
B: Infectivity of cell-culture supernatants (Luciferase assay) normalized by the amount of CAp24 determined by ELISA. Cell-culture supernatants were concentrated by ultracentrifugation prior to analysis. Means + SEM of triplicates from three independent experiments.

C: Correlation analysis of cell-associated HIV-1 (CAp24) and cell-associated infectivity after mechanical washes (black) and collagenase D (grey) treatment of infected cells. The rate of decrease in infectivity (Luciferase activity) and the rate of decrease in CAp24 fluorescence intensity (flow cytometry) were calculated. Each dot represents one experiment; Spearman $\mathrm{R}^{2}$ coefficients and corresponding $\mathrm{p}$ values are indicated.

\section{Supplementary Figure 7}

A: Structured Illumination Microscopy (SIM) showing transfer of HIV-1 MAp17+ collagen + clusters at the interface between $\mathrm{T}$ cells infected by HIV-1 ( $\mathrm{ACH} 2)$ and a target $\mathrm{T}$ cell (CEM cells *, grey). Scale bars: $5 \mu \mathrm{m}$.

B: Left: Confocal fluorescence image of a target CEM T cell (prestained with Cell Trace Violet, grey) carrying a ECM-associated HIV-1 cluster staining positive for HIV-1 MAp17 (red), collagen (green) and agrin (blue). Virus-ECM cluster was captured after $30 \mathrm{~min}$ of coculture with HIV-1-infected $\mathrm{ACH} 2$ cells prestained with the Ace collagen probe. Scale bar: $5 \mu \mathrm{m}$.

Right: Fraction of target CEM cells carrying ECM-associated HIV-1 clusters after 10, 30 and 90 min of coculture with $\mathrm{ACH} 2$ cells.

A: Structured Illumination Microscopy (SIM) of a target CD4+ T cell isolated from a HIV-infected patient $\left(\mathrm{CD} 45\right.$ = plasma membrane, grey; no diffuse cytoplasmic $\mathrm{CAp}_{2} 4^{+}$staining $)$carrying a ECMassociated HIV-1 cluster staining positive for HIV-1 CAp24 (red) and collagen (green).

\section{Supplementary Figure 8}

Membrane-bound HIV-1 clusters from ACH2 cells were adsorbed to a glass coverslip and treated (CollD) or not treated (NT) with collagenase D for $7 \mathrm{~h}$ prior fixation and immunostaining. 
A: Pattern of Env gp120 immunostaining (red) observed by confocal microscopy and quantification of Env patterns $(\mathrm{N}=50$ cells/condition).

B: Correlative Confocal-Scanning Electron Micrograph of HIV-1 clusters. Top left panel: confocal fluorescence image of Env gp120 immunostaining (red). Scale bar: $5 \mu \mathrm{m}$. Top right panel: Scanning Electron Micrograph of the same VEC.

C: Enlargements illustrating changes in architecture of membrane bound HIV-1 cluster after CollD treatment. Scale bars: $1 \mu \mathrm{m}$ and $100 \mathrm{~nm}$. Representative of 2 independent experiments.

D: Infectivity of membrane-bound HIV-1 clusters adsorbed to a glass coverslip, treated or untreated with CollD (Luciferase assay). Means + SEM from 2 independent experiments.

\section{Supplementary Figure 9}

A: Inhibitory effect of AMD3100 on Virus-ECM cluster (VEC) spread: The same experimental set-up as in Figure 8A was used, except that reporter $\mathrm{T}$ cells were pre-incubated for $1 \mathrm{~h}$ with a range of AMD3100 concentrations prior to coculture with infected cells. Residual infectivity of NT (red), M (blue) and $\mathrm{M}+\mathrm{FV}$ (purple) cells in the presence of a range of AMD3100 concentrations. Means + SEM of 3 independent experiments (Mann-Whitney test). Left panel: at equivalent CAp24 amounts (Q=Q'). Right panel: at equivalent infectivity in the absence of drug (Q’> $\left.)^{\prime}\right)$.

\section{B: Inhibitory effects of AMD3100 and of bNAbs on HIV-1 VEC-mediated (cyan) and cell-free} virus (pink) spread, at equivalent infectivity in the absence of drug (Q’>>Q). The inhibitory effect on the HIV-1 VECs was calculated by subtracting the residual infectivity of untreated and washed cells (NT-W), and the inhibitory effect on cell-free HIV-1 was calculated by subtracting the residual infectivity of washed cells complemented or not complemented with cell-free virus $((\mathrm{W}+\mathrm{FV})-\mathrm{W}$ cells). Means + SEM of 3 independent experiments (Mann-Whitney test)

See Fig. 7A for complementary information. 


\section{REFERENCES}

Agosto, L.M., Uchil, P.D., and Mothes, W. (2015). HIV cell-to-cell transmission: effects on pathogenesis and antiretroviral therapy. Trends Microbiol 23, 289-295.

Alfsen, A., Yu, H., Magerus-Chatinet, A., Schmitt, A., and Bomsel, M. (2005). HIV-1-infected blood mononuclear cells form an integrin- and agrin-dependent viral synapse to induce efficient HIV-1 transcytosis across epithelial cell monolayer. Mol Biol Cell 16, 4267-4279.

Altan-Bonnet, N., and Chen, Y.H. (2015). Intercellular Transmission of Viral Populations with Vesicles. J Virol 89, 12242-12244.

Alvarez, R.A., Barria, M.I., and Chen, B.K. (2014). Unique features of HIV-1 spread through T cell virological synapses. PLoS pathogens 10, e1004513.

Andrew, A., and Strebel, K. (2011). The interferon-inducible host factor bone marrow stromal antigen $2 /$ tetherin restricts virion release, but is it actually a viral restriction factor? J Interferon Cytokine Res 31, 137-144.

Beghini, M., Montes, J.M., Rodrigues, D.B., Teixeira, V.P., and Pereira, S.A. (2015). Reduction of immunity in HIV-infected individuals: can fibrosis induce hypoplasia in palatine and lingual tonsils of individuals with HIV infection? Pathology, research and practice 211,27-35.

Bobardt, M.D., Saphire, A.C., Hung, H.C., Yu, X., Van der Schueren, B., Zhang, Z., David, G., and Gallay, P.A. (2003). Syndecan captures, protects, and transmits HIV to T lymphocytes. Immunity 18 , 27-39.

Boerboom, R.A., Krahn, K.N., Megens, R.T., van Zandvoort, M.A., Merkx, M., and Bouten, C.V. (2007). High resolution imaging of collagen organisation and synthesis using a versatile collagen specific probe. J Struct Biol 159, 392-399.

Boulle, M., Muller, T.G., Dahling, S., Ganga, Y., Jackson, L., Mahamed, D., Oom, L., Lustig, G., Neher, R.A., and Sigal, A. (2016). HIV Cell-to-Cell Spread Results in Earlier Onset of Viral Gene Expression by Multiple Infections per Cell. PLoS pathogens 12, e1005964.

Cameron, P.U., Freudenthal, P.S., Barker, J.M., Gezelter, S., Inaba, K., and Steinman, R.M. (1992). Dendritic cells exposed to human immunodeficiency virus type-1 transmit a vigorous cytopathic infection to CD4+ T cells. Science 257, 383-387.

Casartelli, N., Sourisseau, M., Feldmann, J., Guivel-Benhassine, F., Mallet, A., Marcelin, A.G., Guatelli, J., and Schwartz, O. (2010). Tetherin restricts productive HIV-1 cell-to-cell transmission. PLoS pathogens 6, e1000955.

Caskey, M., Klein, F., Lorenzi, J.C., Seaman, M.S., West, A.P., Jr., Buckley, N., Kremer, G., Nogueira, L., Braunschweig, M., Scheid, J.F., et al. (2015). Viraemia suppressed in HIV-1-infected humans by broadly neutralizing antibody 3BNC117. Nature 522, 487-491.

Chen, B.K. (2012). T cell virological synapses and HIV-1 pathogenesis. Immunologic research 54, 133-139.

Chen, P., Hubner, W., Spinelli, M.A., and Chen, B.K. (2007). Predominant mode of human immunodeficiency virus transfer between $\mathrm{T}$ cells is mediated by sustained Env-dependent neutralization-resistant virological synapses. J Virol 81, 12582-12595.

Chen, Y.H., Du, W., Hagemeijer, M.C., Takvorian, P.M., Pau, C., Cali, A., Brantner, C.A., Stempinski, E.S., Connelly, P.S., Ma, H.C., et al. (2015). Phosphatidylserine vesicles enable efficient en bloc transmission of enteroviruses. Cell 160, 619-630.

Costiniuk, C.T., and Jenabian, M.A. (2014). Cell-to-cell transfer of HIV infection: implications for HIV viral persistence. J Gen Virol 95, 2346-2355.

Dahabieh, M.S., Battivelli, E., and Verdin, E. (2015). Understanding HIV latency: the road to an HIV cure. Annu Rev Med 66, 407-421.

Dale, B.M., McNerney, G.P., Thompson, D.L., Hubner, W., de Los Reyes, K., Chuang, F.Y., Huser, T., and Chen, B.K. (2011). Cell-to-cell transfer of HIV-1 via virological synapses leads to endosomal virion maturation that activates viral membrane fusion. Cell host \& microbe 10, 551-562. 
de Chaumont, F., Dallongeville, S., Chenouard, N., Herve, N., Pop, S., Provoost, T., Meas-Yedid, V., Pankajakshan, P., Lecomte, T., Le Montagner, Y., et al. (2012). Icy: an open bioimage informatics platform for extended reproducible research. Nat Methods 9, 690-696.

de Witte, L., Bobardt, M., Chatterji, U., Degeest, G., David, G., Geijtenbeek, T.B., and Gallay, P. (2007). Syndecan-3 is a dendritic cell-specific attachment receptor for HIV-1. Proceedings of the National Academy of Sciences of the United States of America 104, 19464-19469.

Del Portillo, A., Tripodi, J., Najfeld, V., Wodarz, D., Levy, D.N., and Chen, B.K. (2011). Multiploid inheritance of HIV-1 during cell-to-cell infection. J Virol 85, 7169-7176.

Dimitrov, D.S., Willey, R.L., Sato, H., Chang, L.J., Blumenthal, R., and Martin, M.A. (1993). Quantitation of human immunodeficiency virus type 1 infection kinetics. J Virol 67, 2182-2190.

Duncan, C.J., Williams, J.P., Schiffner, T., Gartner, K., Ochsenbauer, C., Kappes, J., Russell, R.A., Frater, J., and Sattentau, Q.J. (2014). High-multiplicity HIV-1 infection and neutralizing antibody evasion mediated by the macrophage-T cell virological synapse. J Virol 88, 2025-2034.

Estes, J.D. (2009). Role of collagen deposition in lymphatic tissues and immune reconstruction during HIV-1 and SIV infections. Curr HIV/AIDS Rep 6, 29-35.

Girish, V., and Vijayalakshmi, A. (2004). Affordable image analysis using NIH Image/ImageJ. Indian J Cancer 41, 47.

Haase, A.T. (1999). Population biology of HIV-1 infection: viral and CD4+ T cell demographics and dynamics in lymphatic tissues. Annu Rev Immunol 17, 625-656.

Heymann, J.A., Shi, D., Kim, S., Bliss, D., Milne, J.L., and Subramaniam, S. (2009). 3D imaging of mammalian cells with ion-abrasion scanning electron microscopy. J Struct Biol 166, 1-7.

Hohenberg, H., Mannweiler, K., and Muller, M. (1994). High-pressure freezing of cell suspensions in cellulose capillary tubes. J Microsc 175, 34-43.

Hubner, W., McNerney, G.P., Chen, P., Dale, B.M., Gordon, R.E., Chuang, F.Y., Li, X.D., Asmuth, D.M., Huser, T., and Chen, B.K. (2009). Quantitative 3D video microscopy of HIV transfer across T cell virological synapses. Science 323, 1743-1747.

Jolly, C. (2010). T cell polarization at the virological synapse. Viruses 2, 1261-1278.

Jolly, C., Booth, N.J., and Neil, S.J. (2010). Cell-cell spread of human immunodeficiency virus type 1 overcomes tetherin/BST-2-mediated restriction in T cells. J Virol 84, 12185-12199.

Jolly, C., Kashefi, K., Hollinshead, M., and Sattentau, Q.J. (2004). HIV-1 cell to cell transfer across an Env-induced, actin-dependent synapse. J Exp Med 199, 283-293.

Jolly, C., Welsch, S., Michor, S., and Sattentau, Q.J. (2011). The regulated secretory pathway in $\mathrm{CD} 4(+) \mathrm{T}$ cells contributes to human immunodeficiency virus type-1 cell-to-cell spread at the virological synapse. PLoS pathogens 7, e1002226.

Kieffer, C., Ladinsky, M.S., Ninh, A., Galimidi, R.P., and Bjorkman, P.J. (2017). Longitudinal imaging of HIV-1 spread in humanized mice with parallel 3D immunofluorescence and electron tomography. Elife 6 .

Ladinsky, M.S., Kieffer, C., Olson, G., Deruaz, M., Vrbanac, V., Tager, A.M., Kwon, D.S., and Bjorkman, P.J. (2014). Electron tomography of HIV-1 infection in gut-associated lymphoid tissue. PLoS pathogens 10, e1003899.

Law, K.M., Komarova, N.L., Yewdall, A.W., Lee, R.K., Herrera, O.L., Wodarz, D., and Chen, B.K. (2016a). In Vivo HIV-1 Cell-to-Cell Transmission Promotes Multicopy Micro-compartmentalized Infection. Cell Rep 15, 2771-2783.

Law, K.M., Satija, N., Esposito, A.M., and Chen, B.K. (2016b). Cell-to-Cell Spread of HIV and Viral Pathogenesis. Adv Virus Res 95, 43-85.

Malbec, M., Porrot, F., Rua, R., Horwitz, J., Klein, F., Halper-Stromberg, A., Scheid, J.F., Eden, C., Mouquet, H., Nussenzweig, M.C., et al. (2013). Broadly neutralizing antibodies that inhibit HIV-1 cell to cell transmission. J Exp Med 210, 2813-2821.

Martin-Serrano, J., and Neil, S.J. (2011). Host factors involved in retroviral budding and release. Nat Rev Microbiol 9, 519-531. 
Mazurov, D., Ilinskaya, A., Heidecker, G., Lloyd, P., and Derse, D. (2010). Quantitative comparison of HTLV-1 and HIV-1 cell-to-cell infection with new replication dependent vectors. PLoS pathogens 6, e1000788.

McArthur, C.P., Wang, Y., Heruth, D., and Gustafson, S. (2001). Amplification of extracellular matrix and oncogenes in tat-transfected human salivary gland cell lines with expression of laminin, fibronectin, collagens I, III, IV, c-myc and p53. Arch Oral Biol 46, 545-555.

McCoy, L.E., Groppelli, E., Blanchetot, C., de Haard, H., Verrips, T., Rutten, L., Weiss, R.A., and Jolly, C. (2014). Neutralisation of HIV-1 cell-cell spread by human and llama antibodies. Retrovirology 11,83.

Mothes, W., Sherer, N.M., Jin, J., and Zhong, P. (2010). Virus cell-to-cell transmission. J Virol 84, 8360-8368.

Mouquet, H. (2014). Antibody B cell responses in HIV-1 infection. Trends in immunology 35, 549561.

Murooka, T.T., Deruaz, M., Marangoni, F., Vrbanac, V.D., Seung, E., von Andrian, U.H., Tager, A.M., Luster, A.D., and Mempel, T.R. (2012). HIV-infected T cells are migratory vehicles for viral dissemination. Nature 490, 283-287.

Murphy, G.E., Narayan, K., Lowekamp, B.C., Hartnell, L.M., Heymann, J.A., Fu, J., and Subramaniam, S. (2011). Correlative 3D imaging of whole mammalian cells with light and electron microscopy. J Struct Biol 176, 268-278.

Neil, S.J. (2013). The antiviral activities of tetherin. Curr Top Microbiol Immunol 371, 67-104.

Neil, S.J., Zang, T., and Bieniasz, P.D. (2008). Tetherin inhibits retrovirus release and is antagonized by HIV-1 Vpu. Nature 451, 425-430.

Nobile, C., Rudnicka, D., Hasan, M., Aulner, N., Porrot, F., Machu, C., Renaud, O., Prevost, M.C., Hivroz, C., Schwartz, O., et al. (2010). HIV-1 Nef inhibits ruffles, induces filopodia, and modulates migration of infected lymphocytes. J Virol 84, 2282-2293.

Olivo-Marin, J.C. (2002). Extraction of spots in biological images using multi scale products. Pattern Recognition 35, 1989-1996

Orenstein, J.M. (2008). Hyperplastic lymphoid tissue in HIV/AIDS: an electron microscopic study. Ultrastruct Pathol 32, 161-169.

Pais-Correia, A.M., Sachse, M., Guadagnini, S., Robbiati, V., Lasserre, R., Gessain, A., Gout, O., Alcover, A., and Thoulouze, M.I. (2010). Biofilm-like extracellular viral assemblies mediate HTLV-1 cell-to-cell transmission at virological synapses. Nat Med 16, 83-89.

Perelson, A.S., Neumann, A.U., Markowitz, M., Leonard, J.M., and Ho, D.D. (1996). HIV-1 dynamics in vivo: virion clearance rate, infected cell life-span, and viral generation time. Science 271, $1582-$ 1586.

Reh, L., Magnus, C., Schanz, M., Weber, J., Uhr, T., Rusert, P., and Trkola, A. (2015). Capacity of Broadly Neutralizing Antibodies to Inhibit HIV-1 Cell-Cell Transmission Is Strain- and EpitopeDependent. PLoS pathogens 11, e1004966.

Reynolds, L., Ullman, C., Moore, M., Isalan, M., West, M.J., Clapham, P., Klug, A., and Choo, Y. (2003). Repression of the HIV-1 5' LTR promoter and inhibition of HIV-1 replication by using engineered zinc-finger transcription factors. Proceedings of the National Academy of Sciences of the United States of America 100, 1615-1620.

Rudnicka, D., Feldmann, J., Porrot, F., Wietgrefe, S., Guadagnini, S., Prevost, M.C., Estaquier, J., Haase, A.T., Sol-Foulon, N., and Schwartz, O. (2009). Simultaneous cell-to-cell transmission of human immunodeficiency virus to multiple targets through polysynapses. J Virol 83, 6234-6246.

Sanjuan, R. (2017). Collective Infectious Units in Viruses. Trends Microbiol 25, 402-412.

Sauter, D. (2014). Counteraction of the multifunctional restriction factor tetherin. Front Microbiol 5 , 163.

Schacker, T.W., Nguyen, P.L., Beilman, G.J., Wolinsky, S., Larson, M., Reilly, C., and Haase, A.T. (2002). Collagen deposition in HIV-1 infected lymphatic tissues and T cell homeostasis. The Journal of clinical investigation 110, 1133-1139. 
Scheid, J.F., Horwitz, J.A., Bar-On, Y., Kreider, E.F., Lu, C.L., Lorenzi, J.C., Feldmann, A., Braunschweig, M., Nogueira, L., Oliveira, T., et al. (2016). HIV-1 antibody 3BNC117 suppresses viral rebound in humans during treatment interruption. Nature 535, 556-560.

Schoofs, T., Klein, F., Braunschweig, M., Kreider, E.F., Feldmann, A., Nogueira, L., Oliveira, T., Lorenzi, J.C., Parrish, E.H., Learn, G.H., et al. (2016). HIV-1 therapy with monoclonal antibody 3BNC117 elicits host immune responses against HIV-1. Science 352, 997-1001.

Seligman, A.M., Wasserkrug, H.L., and Hanker, J.S. (1966). A new staining method (OTO) for enhancing contrast of lipid--containing membranes and droplets in osmium tetroxide--fixed tissue with osmiophilic thiocarbohydrazide(TCH). J Cell Biol 30, 424-432.

Sewald, X., Ladinsky, M.S., Uchil, P.D., Beloor, J., Pi, R., Herrmann, C., Motamedi, N., Murooka, T.T., Brehm, M.A., Greiner, D.L., et al. (2015). Retroviruses use CD169-mediated trans-infection of permissive lymphocytes to establish infection. Science 350, 563-567.

Sewald, X., Motamedi, N., and Mothes, W. (2016). Viruses exploit the tissue physiology of the host to spread in vivo. Curr Opin Cell Biol 41, 81-90.

Sherer, N.M., Lehmann, M.J., Jimenez-Soto, L.F., Horensavitz, C., Pypaert, M., and Mothes, W. (2007). Retroviruses can establish filopodial bridges for efficient cell-to-cell transmission. Nat Cell Biol 9, 310-315.

Smith, A.J., Li, Q., Wietgrefe, S.W., Schacker, T.W., Reilly, C.S., and Haase, A.T. (2010). Host genes associated with HIV-1 replication in lymphatic tissue. Journal of immunology 185, 5417-5424.

Sourisseau, M., Sol-Foulon, N., Porrot, F., Blanchet, F., and Schwartz, O. (2007). Inefficient human immunodeficiency virus replication in mobile lymphocytes. J Virol 81, 1000-1012.

Sowinski, S., Jolly, C., Berninghausen, O., Purbhoo, M.A., Chauveau, A., Kohler, K., Oddos, S., Eissmann, P., Brodsky, F.M., Hopkins, C., et al. (2008). Membrane nanotubes physically connect T cells over long distances presenting a novel route for HIV-1 transmission. Nat Cell Biol 10, 211-219.

Strebel, K. (2013). HIV accessory proteins versus host restriction factors. Curr Opin Virol 3, 692-699.

Sugden, S.M., Bego, M.G., Pham, T.N., and Cohen, E.A. (2016). Remodeling of the Host Cell Plasma Membrane by HIV-1 Nef and Vpu: A Strategy to Ensure Viral Fitness and Persistence. Viruses 8, 67.

Symeonides, M., Lambele, M., Roy, N.H., and Thali, M. (2014). Evidence showing that tetraspanins inhibit HIV-1-induced cell-cell fusion at a post-hemifusion stage. Viruses 6, 1078-1090.

Symeonides, M., Murooka, T.T., Bellfy, L.N., Roy, N.H., Mempel, T.R., and Thali, M. (2015). HIV1-Induced Small T Cell Syncytia Can Transfer Virus Particles to Target Cells through Transient Contacts. Viruses 7, 6590-6603.

Taylor, J.P., Cupp, C., Diaz, A., Chowdhury, M., Khalili, K., Jimenez, S.A., and Amini, S. (1992). Activation of expression of genes coding for extracellular matrix proteins in Tat-producing glioblastoma cells. Proceedings of the National Academy of Sciences of the United States of America 89, 9617-9621.

Thoulouze, M.I., and Alcover, A. (2011). Can viruses form biofilms? Trends Microbiol 19, $257-262$.

Thoulouze, M.I., Lafage, M., Montano-Hirose, J.A., and Lafon, M. (1997). Rabies virus infects mouse and human lymphocytes and induces apoptosis. J Virol 71, 7372-7380.

Thoulouze, M.I., Sol-Foulon, N., Blanchet, F., Dautry-Varsat, A., Schwartz, O., and Alcover, A. (2006). Human immunodeficiency virus type-1 infection impairs the formation of the immunological synapse. Immunity 24, 547-561.

Titanji, B.K., Aasa-Chapman, M., Pillay, D., and Jolly, C. (2013). Protease inhibitors effectively block cell-to-cell spread of HIV-1 between T cells. Retrovirology 10, 161.

Tsai, W.P., Conley, S.R., Kung, H.F., Garrity, R.R., and Nara, P.L. (1996). Preliminary in vitro growth cycle and transmission studies of HIV-1 in an autologous primary cell assay of blood-derived macrophages and peripheral blood mononuclear cells. Virology 226, 205-216.

Tuyama, A.C., Hong, F., Saiman, Y., Wang, C., Ozkok, D., Mosoian, A., Chen, P., Chen, B.K., Klotman, M.E., and Bansal, M.B. (2010). Human immunodeficiency virus (HIV)-1 infects human hepatic stellate cells and promotes collagen I and monocyte chemoattractant protein-1 expression: implications for the pathogenesis of HIV/hepatitis C virus-induced liver fibrosis. Hepatology 52, 612622. 
Van Damme, N., Goff, D., Katsura, C., Jorgenson, R.L., Mitchell, R., Johnson, M.C., Stephens, E.B., and Guatelli, J. (2008). The interferon-induced protein BST-2 restricts HIV-1 release and is downregulated from the cell surface by the viral Vpu protein. Cell host \& microbe 3, 245-252.

Vigneault, F., Woods, M., Buzon, M.J., Li, C., Pereyra, F., Crosby, S.D., Rychert, J., Church, G., Martinez-Picado, J., Rosenberg, E.S., et al. (2011). Transcriptional profiling of CD4 T cells identifies distinct subgroups of HIV-1 elite controllers. J Virol 85, 3015-3019.

Zeng, M., Smith, A.J., Wietgrefe, S.W., Southern, P.J., Schacker, T.W., Reilly, C.S., Estes, J.D., Burton, G.F., Silvestri, G., Lifson, J.D., et al. (2011). Cumulative mechanisms of lymphoid tissue fibrosis and T cell depletion in HIV-1 and SIV infections. The Journal of clinical investigation 121, 998-1008.

Zhang, J., Wang, Y., Chu, Y., Su, L., Gong, Y., Zhang, R., and Xiong, S. (2006). Agrin is involved in lymphocytes activation that is mediated by alpha-dystroglycan. FASEB J 20, 50-58.

Zhong, P., Agosto, L.M., Ilinskaya, A., Dorjbal, B., Truong, R., Derse, D., Uchil, P.D., Heidecker, G., and Mothes, W. (2013). Cell-to-cell transmission can overcome multiple donor and target cell barriers imposed on cell-free HIV. PLoS One 8, e53138. 
Cell-associated HIV-1 capsid

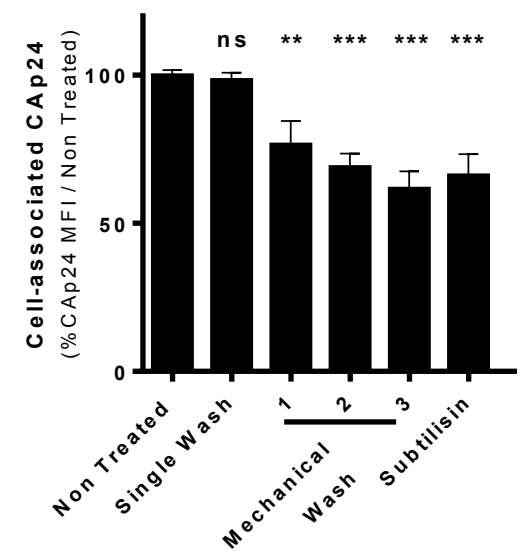

HIV-1

transmission

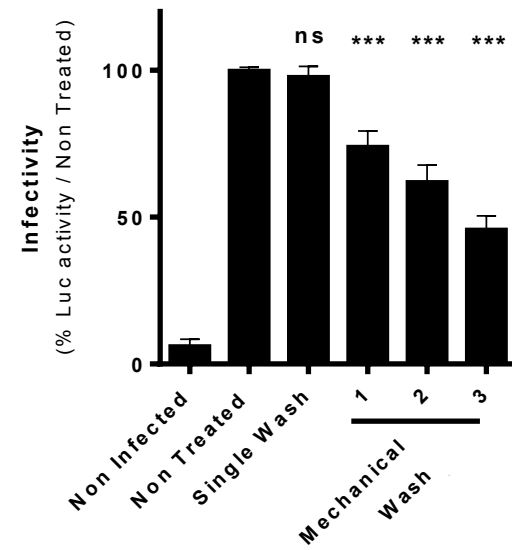

Cell-associated HIV-1 capsid
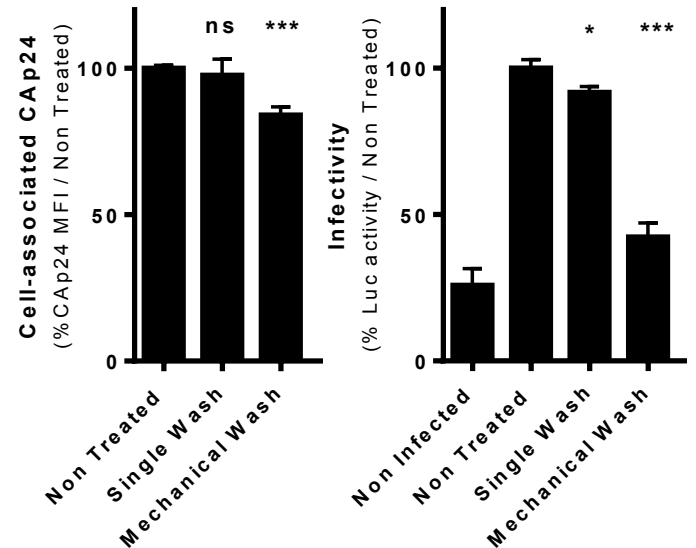

HIV-1 transmission

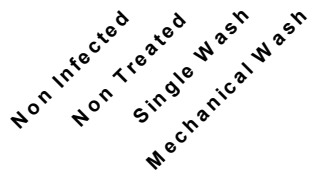

C

Plasma membrane

Chronically infected

T cells $(\mathrm{ACH} 2)$

Primary CD4+ T cell

$+\mathrm{NL4-3}$
HIV-1 MAp17
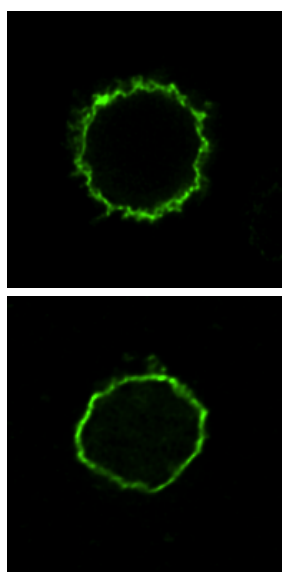

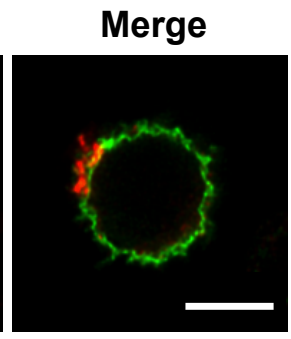

3D projection
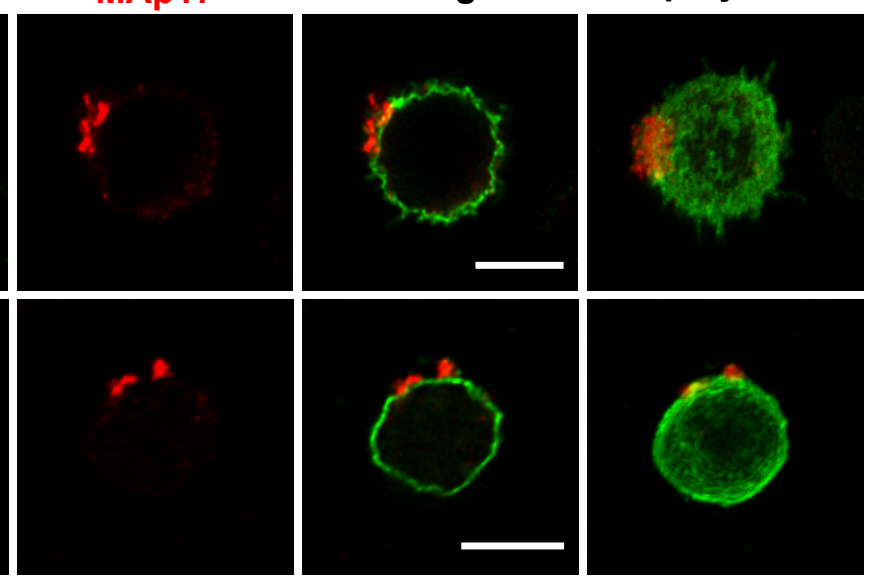

D

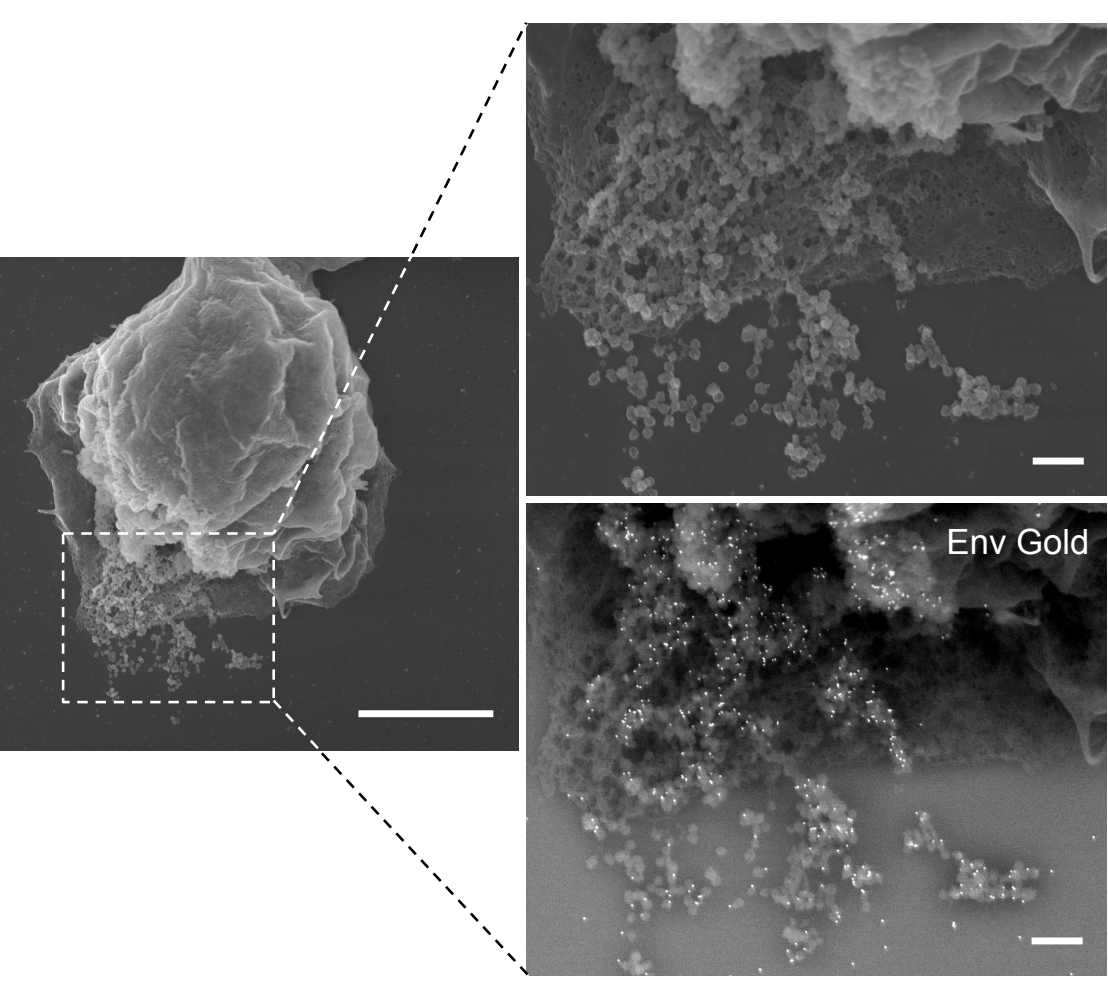

E

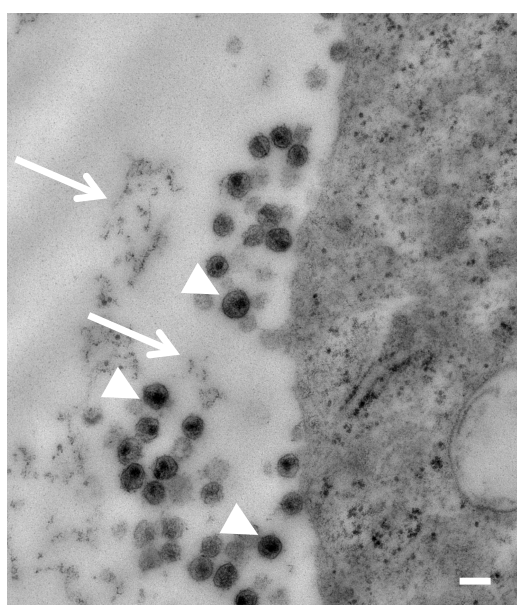

Fig 1 
A

B

HIV-1 CAp24

Collagen

PM

HIV-1 MAp17

Agrin

C

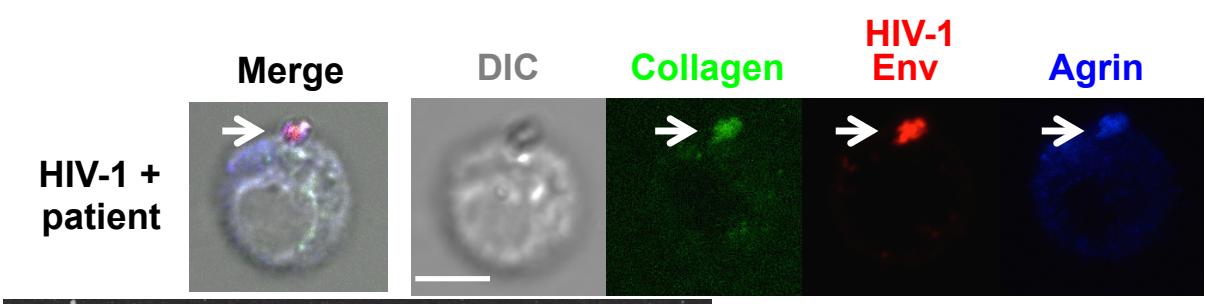

HIV-1 MAp17

PM

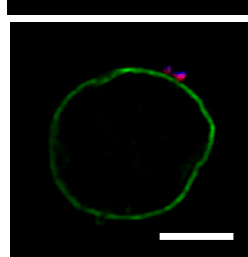

crop
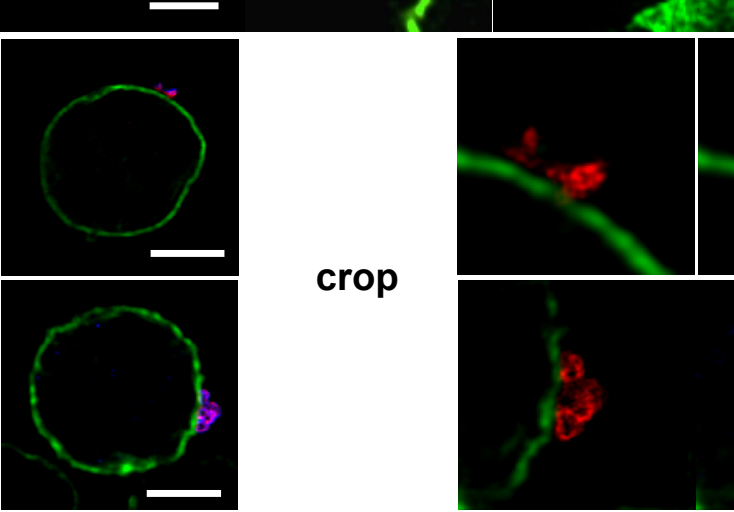

CD4+ T cells

From

HIV-1 infected patients

Merge
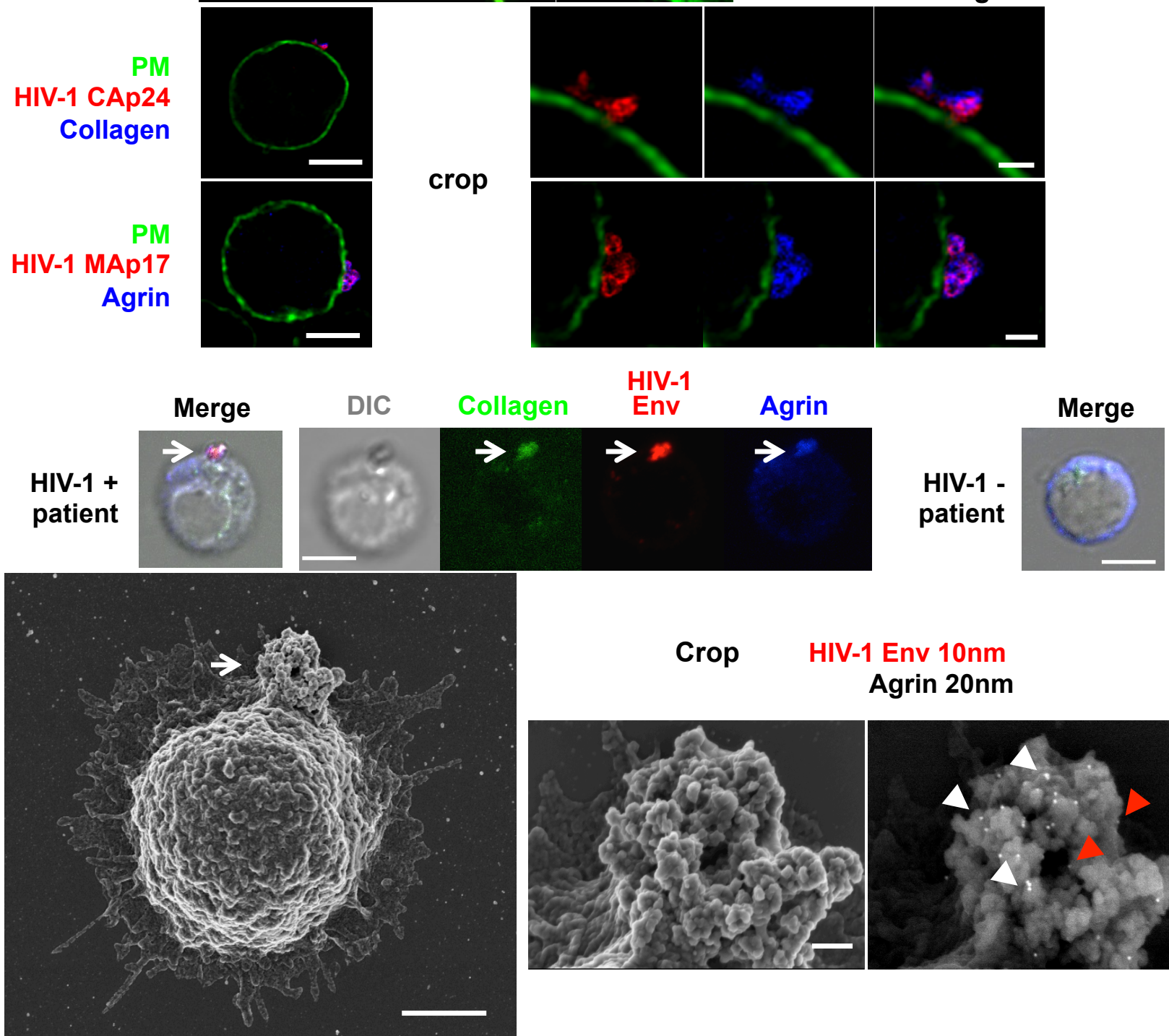

Crop

HIV-1 Env 10nm

Agrin 20nm
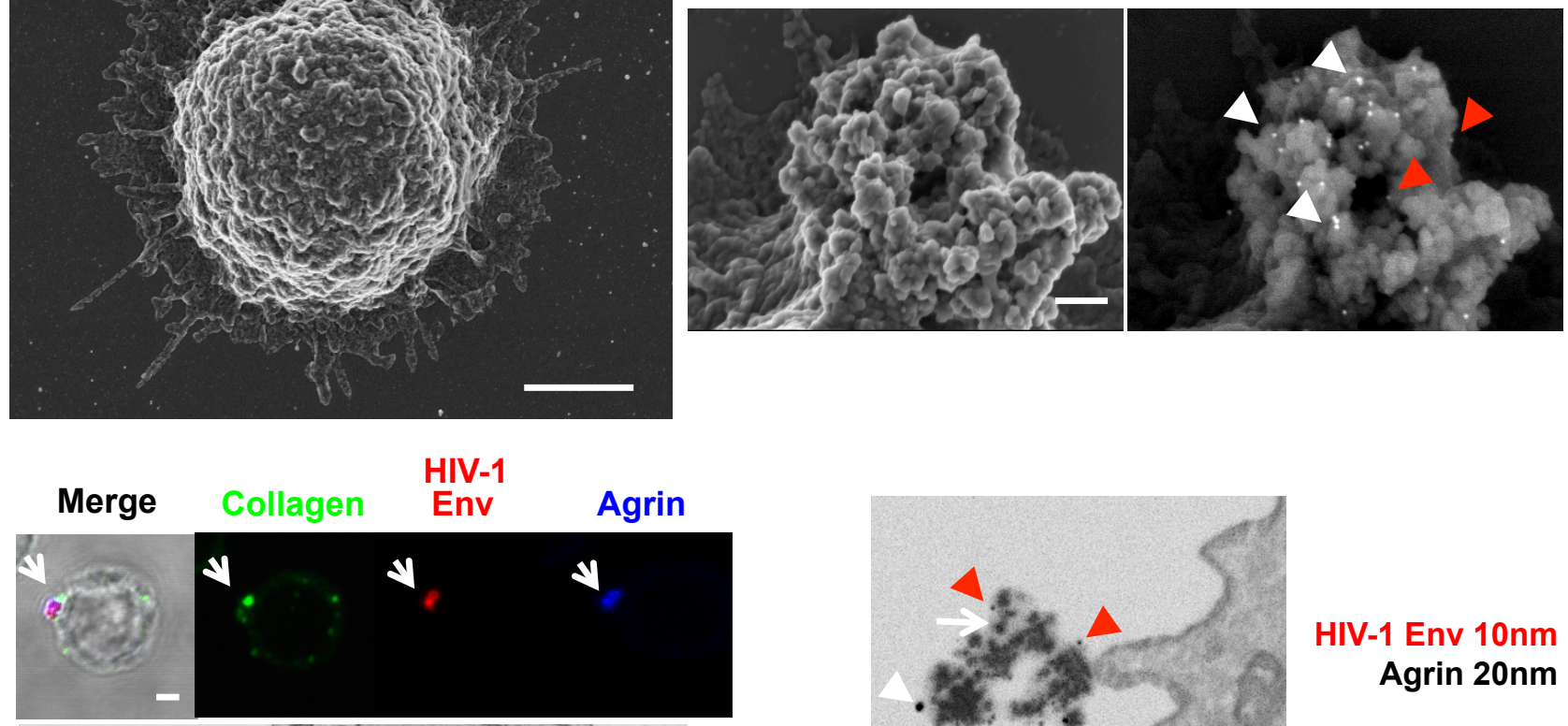

Fig 3

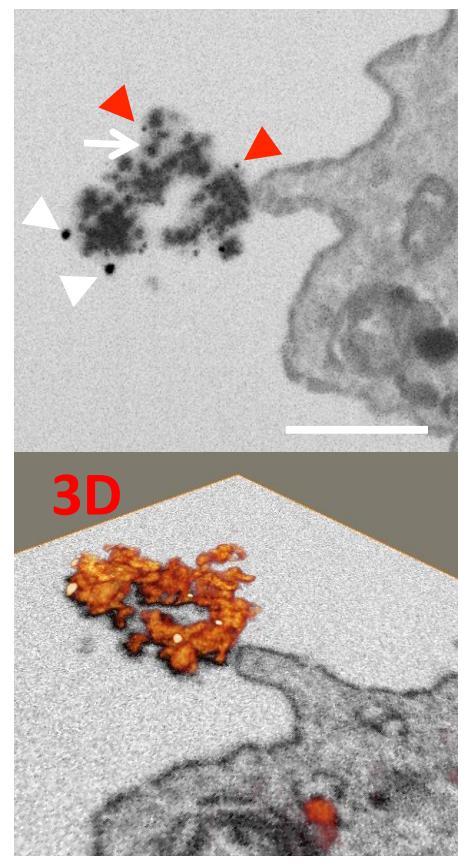

HIV-1 Env 10nm Agrin 20nm 
A

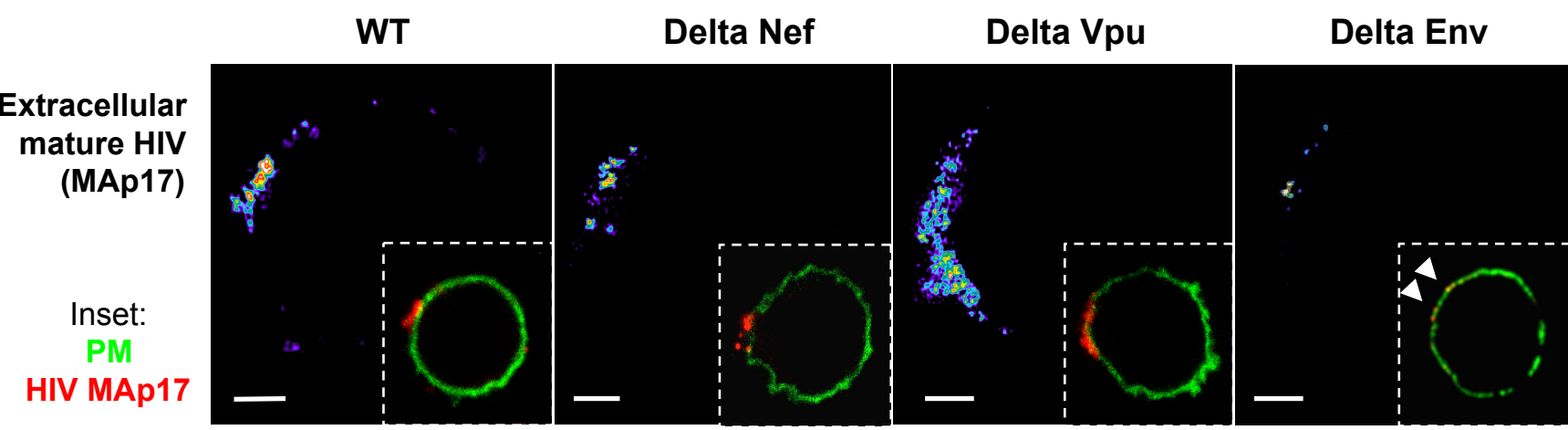

Rainbow

range

B

Infected cells

Mean intensity

of extracellular CAp24/ cell

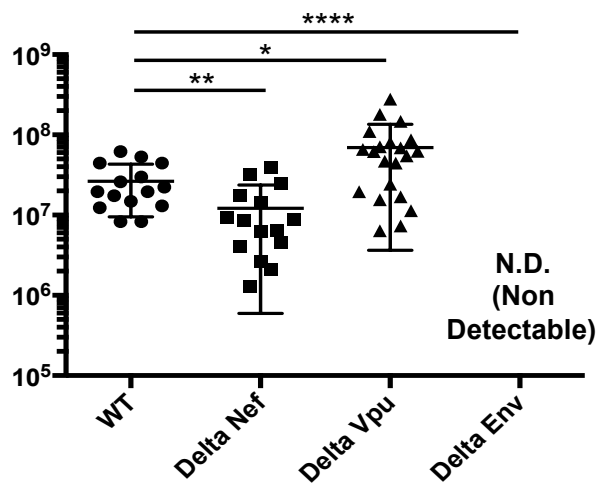

$\mathrm{Nb}$ of extracellular CAp24+ clusters I cell

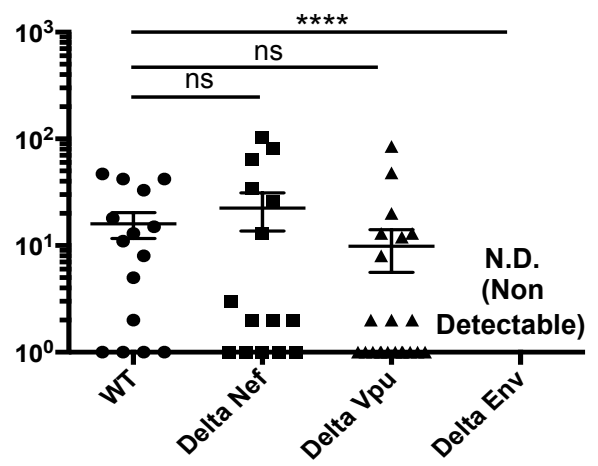

C

Extracellular HIV-1 CAp24+ clusters

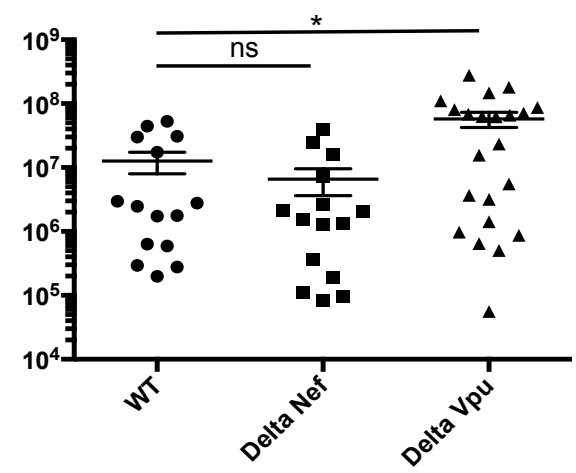

Compaction Index of HIV-1 clusters

$=$ Mean Intensity of clusters/ Size

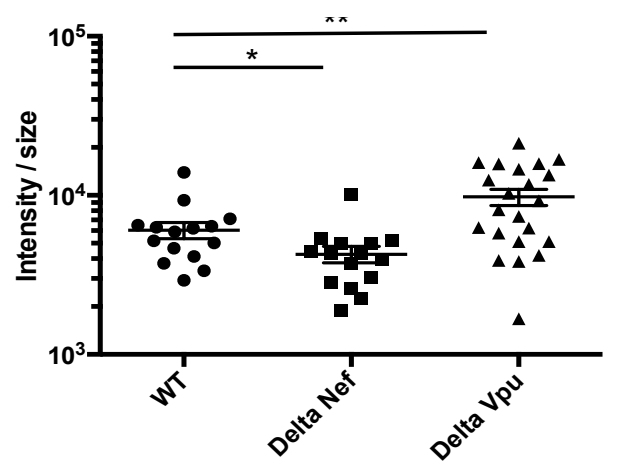

Each dot $=1$ cell

Fig 4 
A

\section{Collagenase $D$ treatment}

Cell-associated HIV-1

HIV-1 transmission
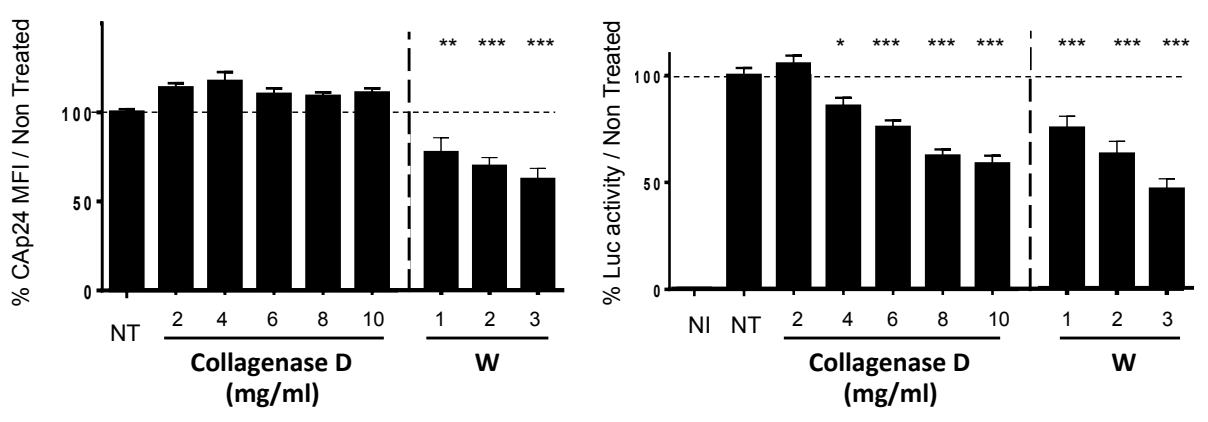

B



$\%$ of HIV-1

cluster-carrying cells
Effects of CollD and mechanical washes treatments on HIV-1 cell surface organization

(MAp17+ clusters)



$$
\begin{aligned}
& \text { Mean size } \\
& \text { of clusters }\left(p x^{3}\right)
\end{aligned}
$$
with a CAp17 dotty pattern

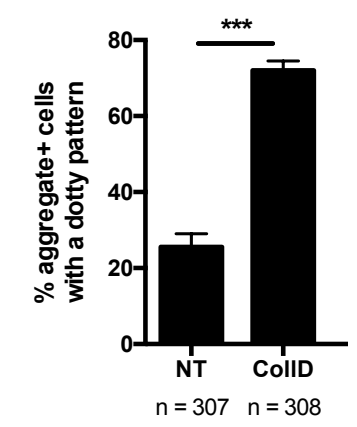

Compaction Index (A.U./px ${ }^{3}$ )

$=$ Mean Intensity of clusters $/$ Size
Spherical spread at the the cell surface (\%)

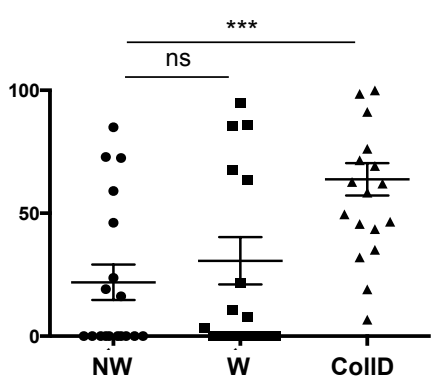

Mean intensity of clusters (A.U.)

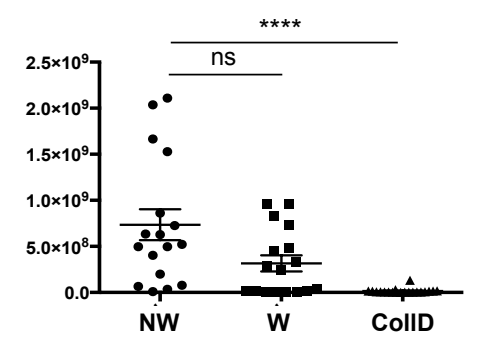

Fig 5

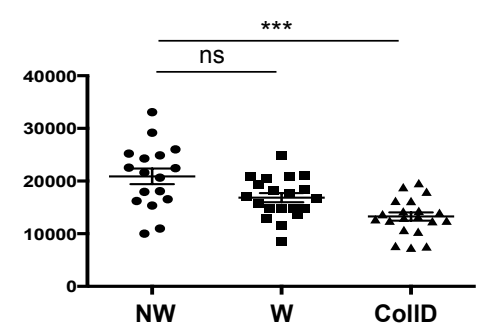


Collagen MAp17

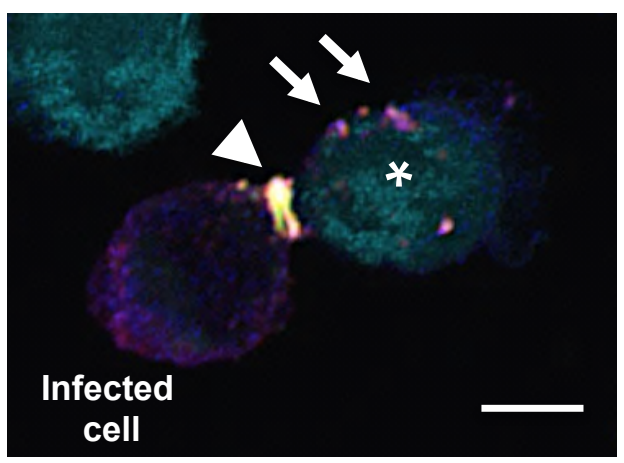

Non infected T cell

Agrin

B

CD4+ cells from HIV-1 infected patients

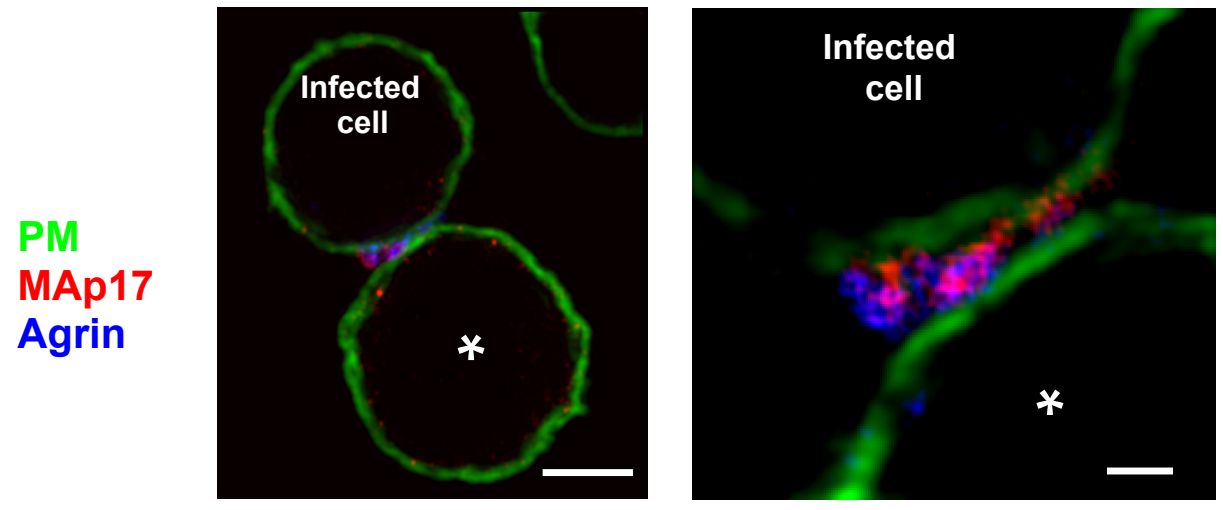

C

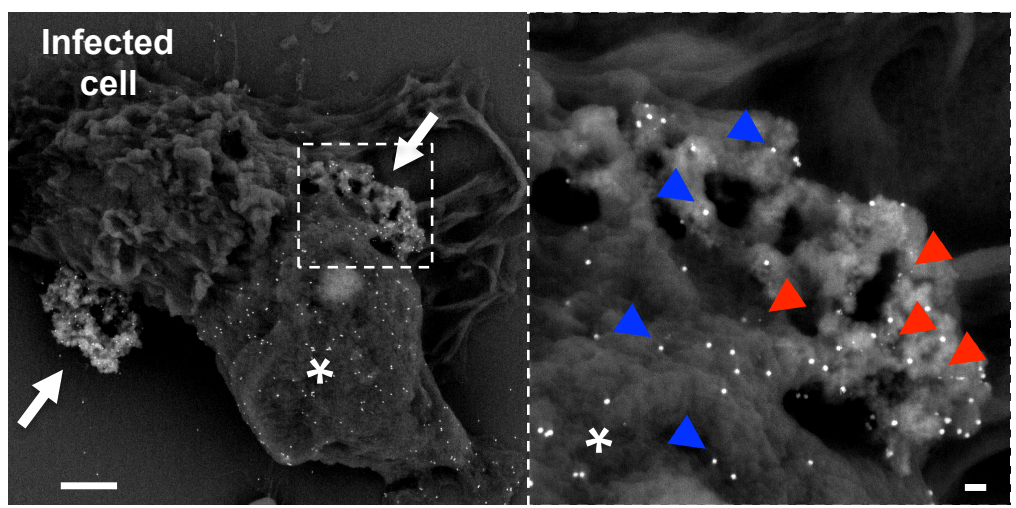

Env (10nm)

Agrin $(20 \mathrm{~nm})$

D

Collagenase D treatment of infected cells prior coculture

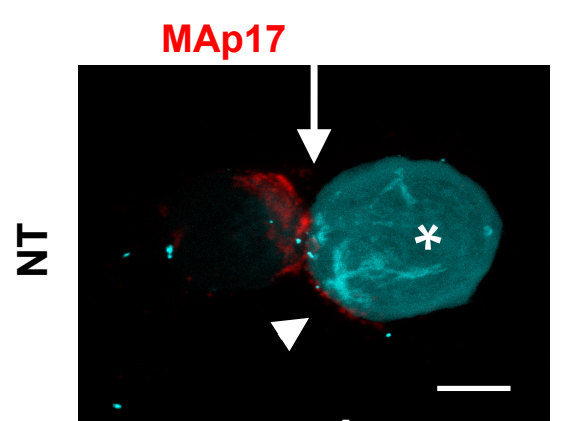

E

Virological synapse formation


$\mathbf{F}$

HIV-1 clustering at the VS

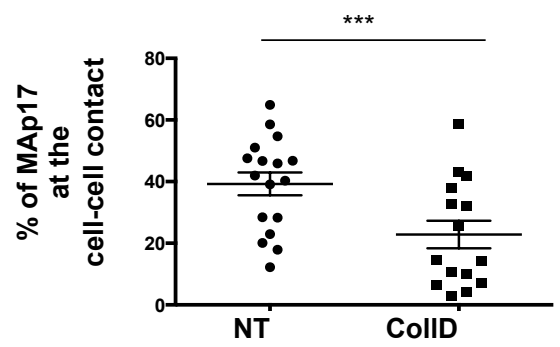

Fig 6 
A

\begin{tabular}{|c|}
\hline $\begin{array}{c}\text { Non treated } \\
\text { cells } \\
\text { NT }\end{array}$ \\
\hline
\end{tabular}

Us-ECM cluster

(VEC) effect

Free virus

(FV) effect

B

\section{(FV)}

Mechanically
washed cells
W

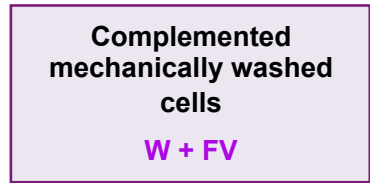

$(0)$

Mechanical washes

(extensive pipetting)<smiles>CC1(C)C2CCCC1C2</smiles><smiles>c1ccccc1</smiles>

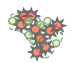

Detached

Virus-ECM clusters ELISA

$\mathbf{Q}=$ Quantity of CAp24

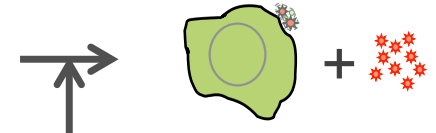

桡

Free virus

from the culture SN

Q' CAp24
Co-culture assay



C

HIV-1 Env

Agrin

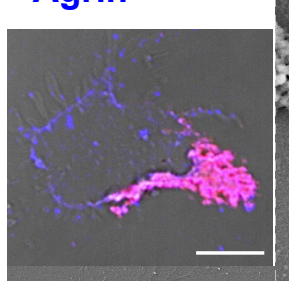

$$
\text { Inset } 1
$$
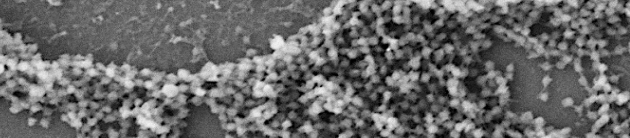

7)
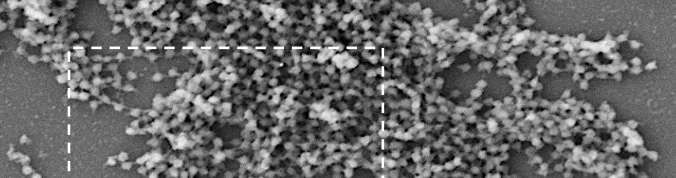

SEM
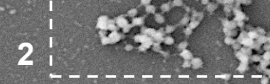

oris? 3

1

D

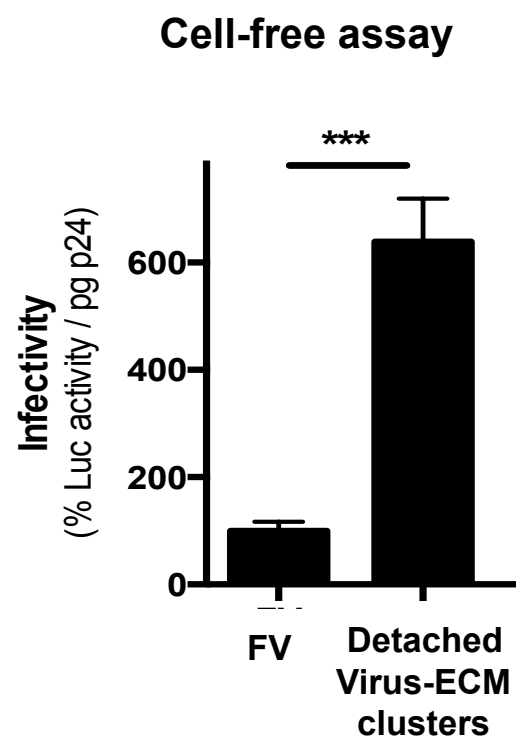

E

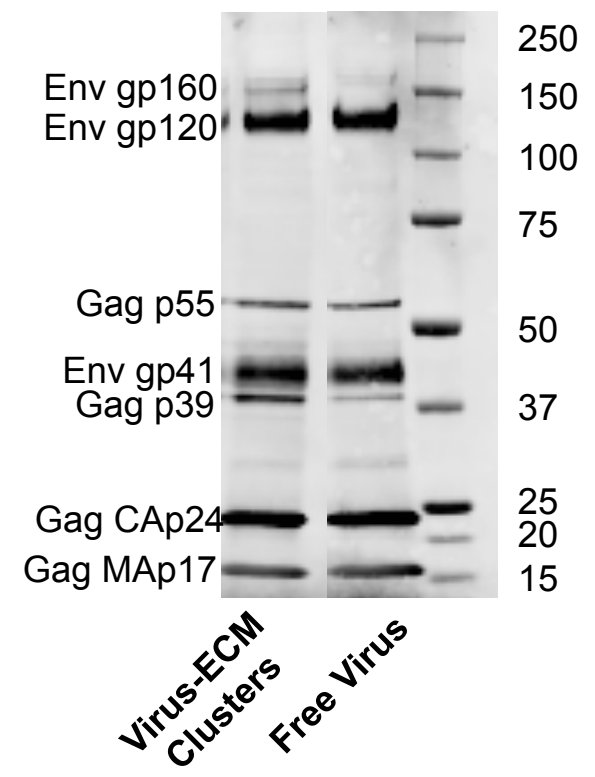

Fig 7 
Equivalent CAp24 $\left(Q^{\prime}=Q\right)$

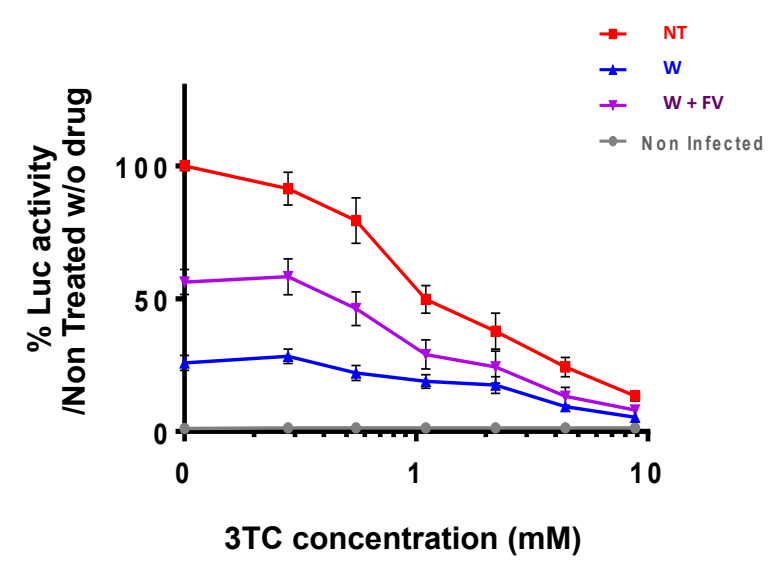

Equal infectivity

$\left(Q^{\prime}>Q\right)$

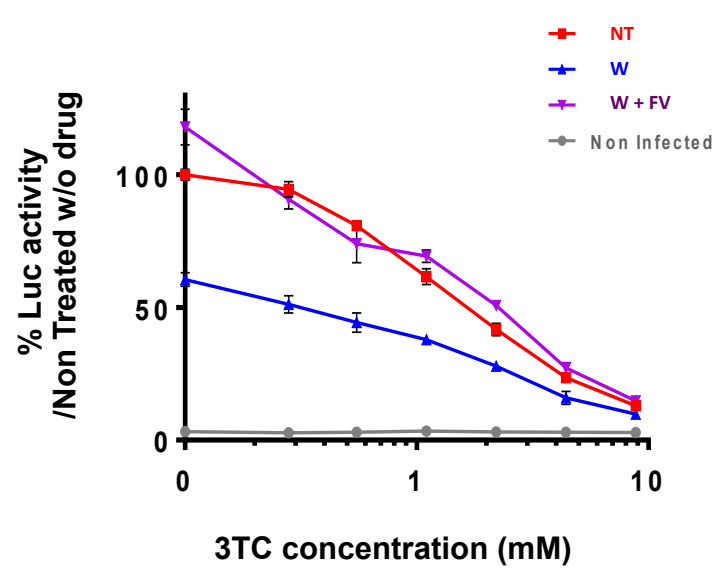

3TC concentration (mM) $\begin{aligned} \mathbf{C} & \quad{ }^{N T} \\ & =\mathrm{w} \\ & \neq \mathrm{W}+\mathrm{FV} \\ & \rightarrow \text { Non Infected }\end{aligned}$

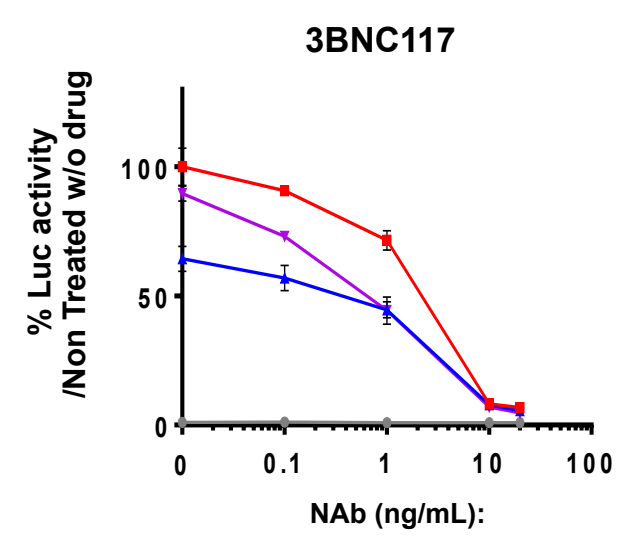

Infectivity in the presence of Nabs

Equal infectivity

( $\left.Q^{\prime}>Q\right)$

PG16

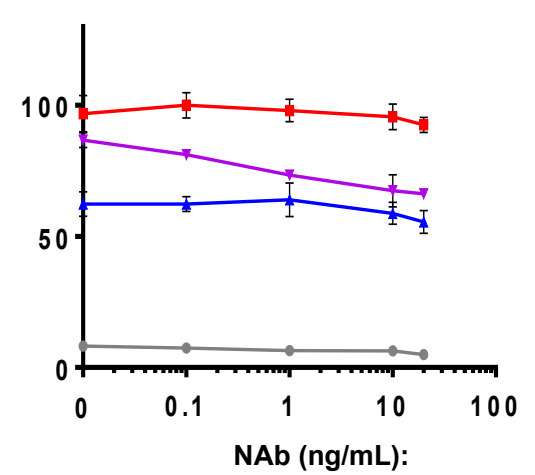

PGT121

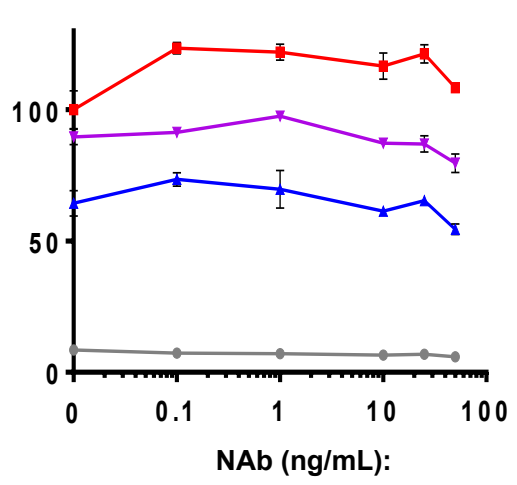

D 3BNC117 inhibition

$+\quad$ NT
$+\quad w$

$+\quad \mathrm{W}+\mathrm{FV}$

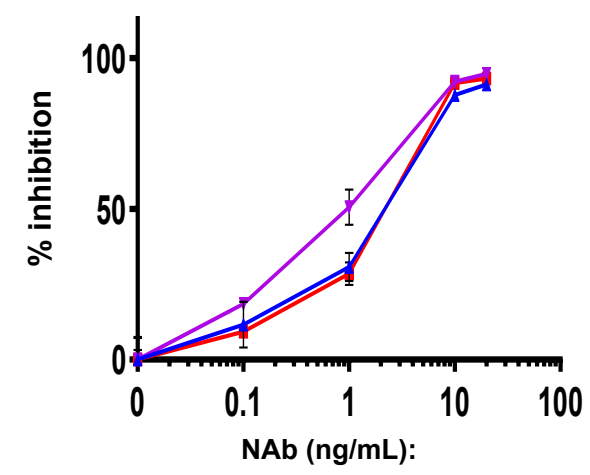

Fig 8 


\begin{tabular}{|c|c|c|c|c|}
\hline Cell type & Virus & $\begin{array}{l}\text { Coreceptor } \\
\text { usage }\end{array}$ & $\%$ p24+ cells & $\begin{array}{l}\% \text { p24+ cells carrying } \\
\text { extracellular viral material }\end{array}$ \\
\hline \multicolumn{5}{|c|}{ Laboratory strains } \\
\hline ACH2 & NL4-3 & CXCR4 & $89 \pm 8$ & $64 \pm 13$ \\
\hline \multirow{2}{*}{$\begin{array}{c}\text { Primary } \\
\text { CD4+ T cells }\end{array}$} & NL4-3 & CXCR4 & $26 \pm 9$ & $71 \pm 3$ \\
\hline & $\mathrm{BaL}$ & CCR5 & $46 \pm 18$ & $72 \pm 2$ \\
\hline \multicolumn{5}{|c|}{ Virus primary isolates } \\
\hline \multirow{3}{*}{$\begin{array}{c}\text { Primary } \\
\text { CD4+ T cells }\end{array}$} & $\mathrm{Bx} 08$ & CCR5 & $26 \pm 13$ & $71 \pm 3$ \\
\hline & DH12 & Dual tropic & $35 \pm 13$ & $74 \pm 7$ \\
\hline & W132 & Dual tropic & $18 \pm 4$ & $69 \pm 9$ \\
\hline \multicolumn{2}{|c|}{$\begin{array}{c}\text { CD4+ T cells from } \\
\text { HIV-1 infected patients }\end{array}$} & Unknown & $5 \pm 3$ & $49 \pm 8$ \\
\hline
\end{tabular}

\section{Table 1}




\section{TransBioHIV cohort}

HIV-1- infected viremic patients were selected in Bicêtre Hospital

\begin{tabular}{|c|c|c|c|c|c|c|}
\hline Patient & Sex & Age & $\begin{array}{l}\text { CD4 count } \\
/ \mathrm{mm}^{3}\end{array}$ & $\begin{array}{c}\text { RNA } \\
\text { copies/ml }\end{array}$ & Treatment & $\begin{array}{c}\text { Time under } \\
\text { treatment } \\
\text { before sampling } \\
\text { (weeks) }\end{array}$ \\
\hline 01 & $\mathrm{M}$ & 30 & 426 & 24649 & $\begin{array}{c}\text { FTC + TDF + } \\
\text { RVP }\end{array}$ & 4 \\
\hline 02 & $\mathrm{M}$ & 54 & 280 & 232 & $\begin{array}{c}\mathrm{FTC}+\mathrm{TDF}+ \\
\mathrm{ATZ} / \mathrm{rtv}\end{array}$ & 6 \\
\hline 03 & M & 48 & 70 & 189,980 & $\begin{array}{c}\mathrm{FTC}+\mathrm{TDF}+ \\
\mathrm{RAL}\end{array}$ & 1 \\
\hline 04 & $\mathrm{M}$ & 27 & 456 & 41,450 & 0 & 0 \\
\hline 05 & M & 35 & 782 & 37,490 & 0 & 0 \\
\hline 06 & M & 28 & 531 & 27,638 & 0 & 0 \\
\hline $\begin{array}{l}\text { the time } \\
\text { atient } 1 \text {, } \\
\text { vailable. } \\
\text { altégravil }\end{array}$ & 100 & l: & 4 coun & $\begin{array}{l}-1 R N A v \\
R N A \text { vir } \\
R P V: R t\end{array}$ & vere availabl & $\begin{array}{l}\text { atient } 2,5 \text { and } 6 . \text { Fo } \\
\text { blood sampling wer } \\
\text { Rtv: Ritonavir, } R A L\end{array}$ \\
\hline
\end{tabular}

Table 2 